This item was submitted to Loughborough's Research Repository by the author.

Items in Figshare are protected by copyright, with all rights reserved, unless otherwise indicated.

\title{
An integrated approach for modeling sustainability risks in freight transportation systems
}

PLEASE CITE THE PUBLISHED VERSION

https://doi.org/10.1111/risa.13435

PUBLISHER

Wiley

VERSION

AM (Accepted Manuscript)

\section{PUBLISHER STATEMENT}

This is the peer reviewed version of the following article: Choudhary, D., Shankar, R. and Choudhary, A. (2020), An Integrated Approach for Modeling Sustainability Risks in Freight Transportation Systems. Risk Analysis, 40: 858-883, which has been published in final form at https://doi.org/10.1111/risa.13435. This article may be used for non-commercial purposes in accordance with Wiley Terms and Conditions for Use of SelfArchived Versions.

\section{LICENCE}

CC BY-NC-ND 4.0

\section{REPOSITORY RECORD}

Choudhary, Divya, Ravi Shankar, and Alok Choudhary. 2019. "An Integrated Approach for Modeling Sustainability Risks in Freight Transportation Systems". Loughborough University. https://hdl.handle.net/2134/11359697.v1. 
An Integrated Approach for Modeling Sustainability Risks in Freight Transportation Systems

\author{
Divya Choudhary, ${ }^{*}$ Ravi Shankar, ${ }^{2}$ Alok Choudhary ${ }^{3}$ \\ ${ }^{1}$ Indian Institute of Management Sambalpur, Odisha, India \\ ${ }^{2}$ Indian Institute of Technology Delhi, New-Delhi, India \\ ${ }^{3}$ Loughborough University, Loughborough, United Kingdom
}

* Address correspondence to Dr. Divya Choudhary, Indian Institute of Management Sambalpur, Jyoti Vihar, Burla, Sambalpur-768019, Odisha, India; divyachoudhary2626@gmail.com 


\begin{abstract}
Integrating sustainability into freight transportation systems (FTSs) is a complex and challenging task due to the sheer number of inherent sustainability risks. Sustainability risks disrupt the socio-economicenvironmental efficiency of freight operations and act as impediments in the development of sustainable freight transportation systems (SFTSs). The area of sustainability risk management is still unexplored and immature in the operational research domain. This study addresses these research gaps and contributes in a three-fold manner. Firstly, a rigorous approach is used to identify a total of 36 potential sustainability risks uniquely classified into 7 categories for the FTSs. Secondly, the research proposes two prominent perspectives namely, ontological and epistemological perspectives to understand risks and develops a novel framework for managing sustainability risks in FTSs. Thirdly, a novel approach by integrating fuzzy evidential reasoning algorithm (FERA) with expected utility theory is developed to quantitatively model and profile sustainability risk for different risk preferences namely, risk-averse; risk-neutral; and risk-taking scenarios. FERA is a flexible and robust approach, which transforms the experts' inputs into belief structures and aggregates them using the evidence combination rule proposed in Dempster-Shafer Theory to overcome the problem of imprecise results caused by average scoring in existing models. A sensitivity analysis is conducted to demonstrate the robustness of the proposed model. Unlike conventional perception, our study suggests that most of the high priority sustainability risks are behaviorally and socially induced rather than financially driven. The results provide significant managerial implications including a focus on skills development, and on social and behavioral dimensions while managing risks in FTSs.
\end{abstract}

Keywords: Sustainable Freight Transportation Systems; Evidential Reasoning Algorithm; Risk Perspectives; Sustainability Risks 


\section{INTRODUCTION}

Business Communities characterized by rising levels of uncertainty and risky environments are facing frequent unavoidable disruptions recently (Aven, 2016). Business globalization, outsourcing of activities, demand volatility, unreliable suppliers and complex networks are further contributing to the increasing disruptions (Fahimnia, Tang, Davarzani \& Sarkis, 2015). Furthermore, growing awareness on sustainability concerns such as environmental degradation, resource depletion, global warming, natural disasters, gender discrimination, health problems etc. have resulted in the emergence of new risks for the organizations known as "sustainability risks". In line with the definition of risks proposed by Aven and Renn (2009), sustainability risk is uncertainty about the occurrence of an event and severity of the associated economicsocial-environmental consequences on the society, provoking harmful stakeholder reaction. These risks act as impediments in the development of sustainable systems.

Freight transportation (FT) sector is a priority action area for sustainability incorporation due to the associated negative externalities such as fossil fuel depletion, accidents, congestions, air-water-noise pollution, visual intrusion, vibrations, social extrusions etc (Richardson, 2005; SteadieSeifi, Dellaert, Nuijten, Woensel \& Raoufi, 2014; Schliwa \& Armitage, 2015; Bai, Fahimnia \& Sarkis, 2017). In urban areas, about $40 \%$ of noise and air pollution, along with $10-15 \%$ of congestion is attributed to FT (Gan, 2003; Cui, Dodson \& Hal, 2015). Furthermore, Velazquez et al. (2015) claim that CO2 emissions may increase by an additional $109 \%$ by 2050 if FT continues to escalate at the current rate. In order to curb these unsustainable consequences, organizations are stepping beyond the conventional economic focus and adopting the triple bottom line (TBL) framework of sustainability for building sustainable freight transportation systems (SFTSs). Increasing environmental concerns, government regulations and consumer awareness are further adding to the leading impetus towards the development of SFTSs. However, shifting to SFTSs faces a major challenge due to the involvement of numerous uncertainties and inherent sustainability risks (Cavinto, 2004; Rodrigues, Potter \& Naim, 2010; Busse, Schleper, Weilenmann \& Wagner, 2018).These risks can have unanticipated financial consequences and cause environmental damage 
and loss of market reputation (Stackelberg, 2013). To surmount sustainability risks, organizations need to build expertise and knowledge, which should be codified, institutionalized and reinforced throughout freight transportation systems (FTSs) in accordance with Fig. 1. In Fig. 1, our research extends the risk management maturity model proposed by Schlegel and Trent (2015) by integrating sustainability risk attributes in the context of FTSs.

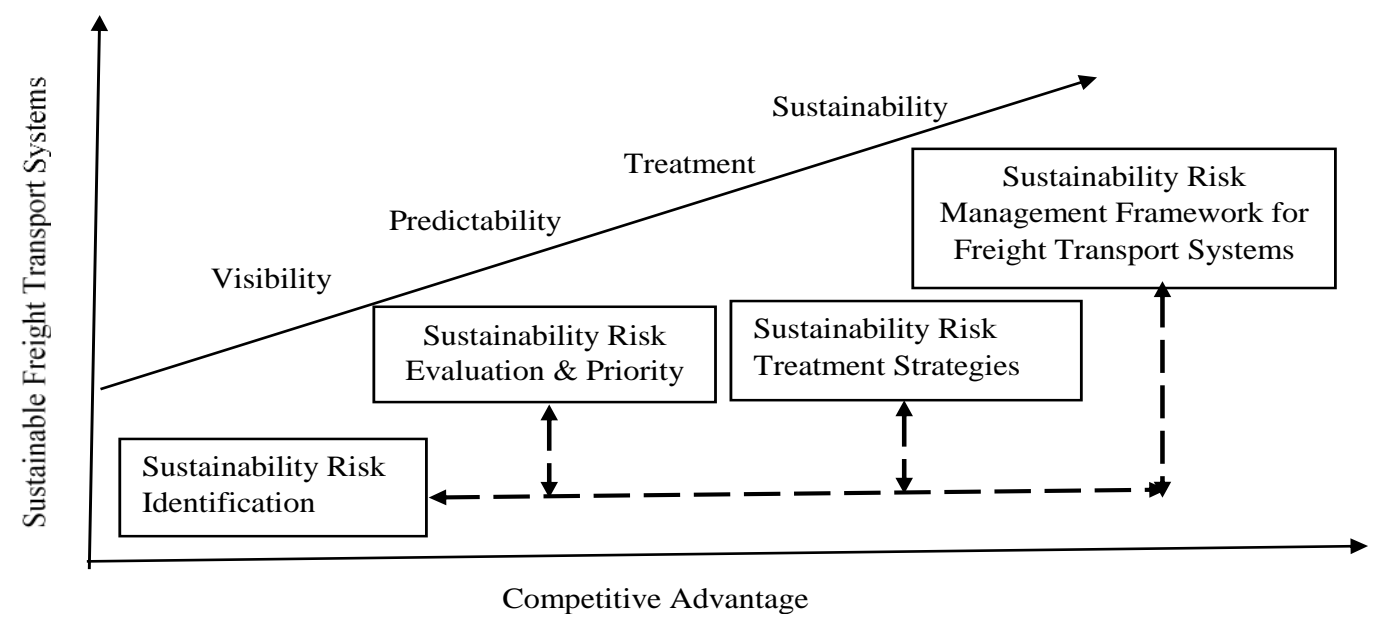

Fig. 1. Enhanced Risk Management Maturity Model for Sustainable Freight Transportation (modified from Schlegel \& Trent, 2015)

Visibility is the first step in a risk management journey during which sustainability risks associated with FT are explored and identified. The second step involves quantification and prioritization of acknowledged risks to gain insights about their consequences and severity. In the third step (treatment stage) strategies are developed to facilitate the sensing and controlling of sustainability risks. These three steps together constitute a sustainability risk management framework (as proposed in Fig. 2), which must be integrated as an integral part of SFTSs for continuous improvement.

Risk is a multidimensional concept and is never absolute as some organizations may view a certain situation as highly risky, while others perceive it as less risky. The extent to which organizations are willing to take risks represent their risk preferences, defined on a continuum from risk-averse to risk-taking. This study seeks to understand and differentiate between risk preferences for better insights. Furthermore, despite having insightful studies in the risk management and sustainability area, a very few studies have addressed 
risk aspects in the context of sustainability. There are still gaps in the literature regarding profiling and assessment of sustainability risks in FTSs. Recent review papers have also highlighted the need to investigate sustainability risks (Brandenburg \& Rebs, 2015; Fahimnia et al., 2015; Aven, 2016; Jaehn, 2016; Reefke \& Sundaram, 2017). Accordingly, a model is developed for the evaluation and profiling of sustainability risks present in FTSs considering three ubiquitous scenarios: risk-averse, risk-neutral and risk-taking. However, it is initially necessary to understand the different risk perspectives to develop appropriate models for better analysis and results.

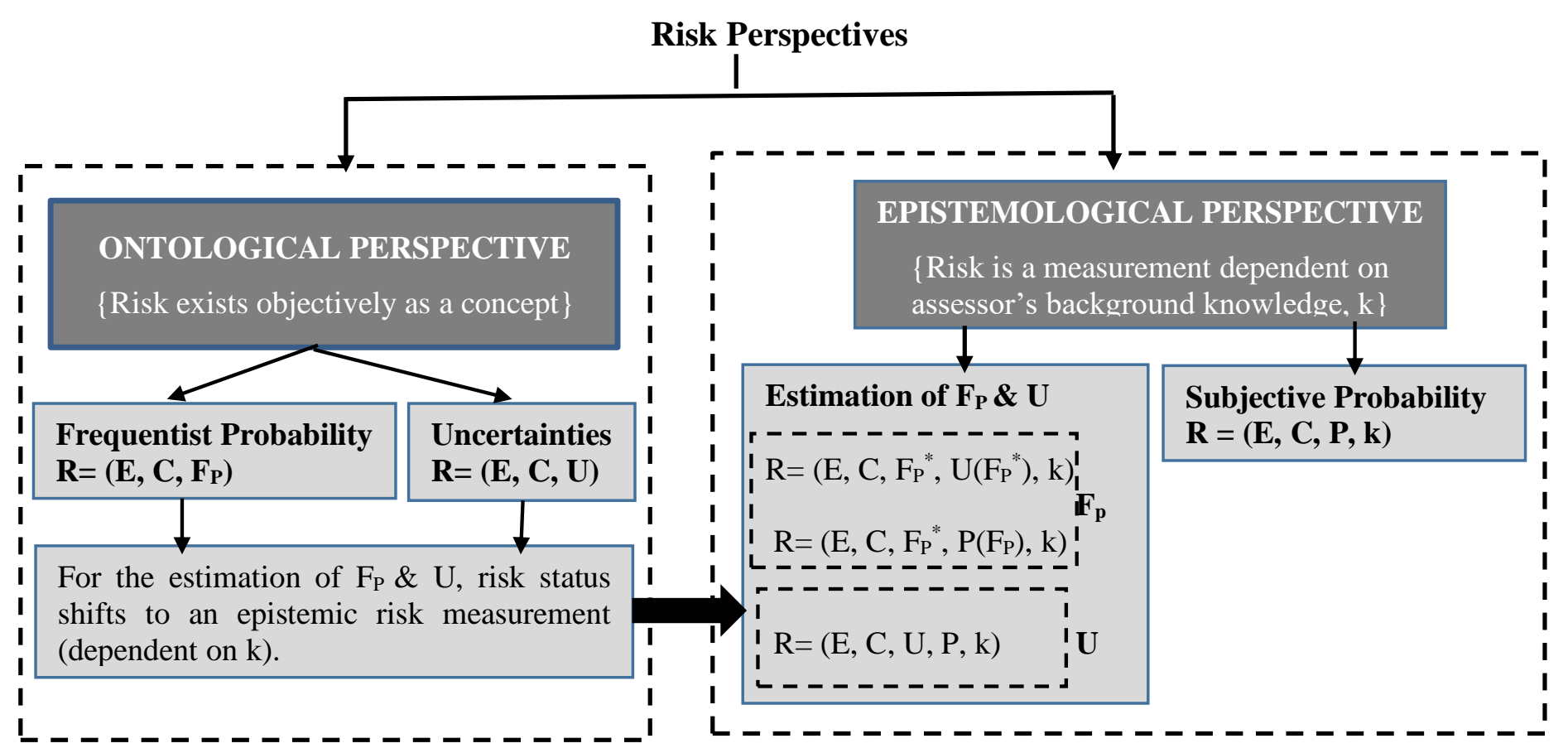

Fig. 2. Different Perspectives to Understand Risks

We propose that there are two prominent perspectives emerging from the literature to understand risks as shown in Fig. 2. One is ontological perspective according to which risk exist objectively in itself as a concept independent of any assessor and other is epistemological perspective in which risk is a measurement (description), dependent on assessor's background knowledge (k). Accordingly, risk exists objectively as a concept but when assessed, risk is dependent on the assessor and hence becomes subjective. This is the crucial nexus between the ontology and the epistemology of risk. In ontological perspective, risk is objectively conceptualized either by frequentist probability $\left(F_{p}\right)$ (Aven, 2018) or uncertainty $(U)$ as $R=$ 
$\left(\mathrm{E}, \mathrm{C}, \mathrm{F}_{\mathrm{p}}\right)$ or $\mathrm{R}=(\mathrm{E}, \mathrm{C}, \mathrm{U})$ where $\mathrm{E}=$ event and $\mathrm{C}=$ consequences. As we move towards the estimation of frequentist probability and degree of uncertainty, the status of risk shifts to an epistemic risk measurement. In epistemological perspective, risk is conceptualized by subjective probability (P) (Aven \& Renn, 2011), conditional on assessor's background knowledge $(\mathrm{k})$ and is represented as $\mathrm{R}=(\mathrm{E}, \mathrm{C}, \mathrm{P}, \mathrm{k})$. Our research is based on the epistemological perspective as sustainability risks can be conceptualized effectively through subjective probability.

The analysis in this research is performed by innovatively using fuzzy evidential reasoning algorithm (FERA) in combination with expected utility theory (EUT). The reasons FERA is used in this research are as follows. Firstly, lack of data necessitates the incorporation of expert judgments for sustainability risk evaluation, which enhances the ambiguity and subjectivity involved in the process. Most of the traditional techniques in literature are insufficient to handle the vague, subjective and incomplete information often provided by experts for risk analysis. FERA can efficiently address the uncertainty and vagueness in linguistic assessments through fuzzy set theory (FST) and evidential reasoning algorithm (ERA) can handle ignorance and subjectivity to provide better and precise results (Liu et al., 2011; Su, Mahadevan, Xu \& Deng, 2015). Secondly, FERA uses a more pragmatic way to represent the linguistic assessment of each attribute in the form of a distributed assessment using belief degree structures. Thirdly, traditional techniques involve averaging of scores on different criteria to quantify risk severity, which results in information loss and imprecise outcomes. FERA synthesizes the linguistic assessments using the evidence combination rule proposed in Dempster-Shafer Theory and thus avoids the loss of useful information in the inference processes (Yang, Wang, Bonsall \& Fang, 2009; Chen, Shu \& Burbey, 2014; Wu, Yan, Wang \& Soares, 2017). Fourthly, EUT transforms the aggregated belief structures into crisp numerical values using different utilities, which facilitates the prioritization and comparison of sustainability risks for different risk preferences. 
In EUT, risk preferences describe the shape of the utility function presumed to represent a person's choices (Von Neumann \& Morgenstern, 1947). A concave curvature of the utility function denotes risk-averse behavior and a convex curvature is evidence for the risk-taking behavior (Weber \& Milliman, 1997). In this study, the decision makers' perceived utility of linguistic terms used for evaluating sustainability risks is recorded for risk-averse, risk-neutral and risk-taking attitudes respectively. These utilities are multiplied with the corresponding aggregated belief degree structures obtained through FERA to compute the risk priority scores of sustainability risks for each risk preference. Accordingly, the prioritized rankings and profiling of sustainability risks associated with FT are obtained for all three risk preferences. A sensitivity analysis is also performed to validate the robustness of the results. The rest of the paper is organized as follows: Section 2 discusses the literature on sustainability risks; Section 3 explains the methodology applied in this research; the practical application of the methodology is illustrated in Section 4; and Section 5 presents the concluding remarks.

\section{SUSTAINABILITY RISKS}

The paradigm shift in business world from the conventional economic focus towards improving the socioenvironmental conduct faces a major challenge due to the associated sustainability risks. These risks are potential threats that adversely impact the integration of TBL framework and disrupt the socio-economicenvironmental performance of a system. One of the unique characteristics of sustainability risks is; they can have detrimental consequences for an organization without disrupting its operations (Giannakis \& Papadopoulos, 2016). The negative outcomes of such risks can include brand image degradation, monetary losses, poor service level, security issues, and customer losses (Mangla, Kumar \& Barua, 2015; Govindan \& Chaudhuri, 2016).

Despite the growing attention towards the link between FT, sustainability and risk management, the issue of sustainability risks in the context of FTSs is still underrepresented in the literature (Marchet, Melacini \& Perotti, 2014; Reefke \& Sundaram, 2017; Shankar, Choudhary \& Jharkharia, 2018). Brandenburg and Rebs 
(2015) acknowledged the same in their review paper as only 8 of the 185 reviewed papers had comprehensively considered the sustainability risks. Few studies have examined the sustainability risks in the context of supply chains. Giannakis and Papadopoulos (2016) analyzed the sustainability risks present in supply chains and suggested measures to control such risks. Busse et al. (2018) developed a model to explore the supply chain sustainability risks using stakeholder network. Mangla et al. (2015) evaluated the risks associated with green supply chain and prioritized them. In another analysis, it is determined that the failure to select the right supplier is the most critical risk for sustainable supply chain management (Hofmann, Busse, Bode \& Henke, 2014). In some of the research, supply chain sustainability risks are examined and supported using stakeholder theory and/or institutional theory (Busse, Kach, \& Bode, 2016; Reinerth, Busse \& Wagner, 2019). According to Hofmann et al. (2014) the materializing mechanism of ordinary and sustainability-related supply chain risks is different as ordinary risks result due to disruptions and impact the supply chain operations while sustainability risks arise due to stakeholder reactions. A brief overview of some of the recent studies on sustainability risks in different domains is presented in Table I.

Table I: A brief overview of recent studies on sustainability risks in different domains

\begin{tabular}{|c|c|}
\hline Author(s) & Research Outline \\
\hline $\begin{array}{l}\text { Kim, Wagner and } \\
\text { Colicchia (2019) }\end{array}$ & $\begin{array}{l}\text { The study examines the magnitude and severity of consequences associated with } \\
\text { supplier sustainability risks (SSRs) and found that it can lead to one percent reduction } \\
\text { in shareholder wealth. }\end{array}$ \\
\hline $\begin{array}{l}\text { Whijethilake and Lama } \\
\qquad \text { (2019) }\end{array}$ & $\begin{array}{l}\text { The paper analyzes the effect of top management commitment and stakeholder pressure } \\
\text { on sustainability risk management and its relationship to sustainability core values and } \\
\text { indicate a positive impact of top management comitment and nagative of stakeholder } \\
\text { pressure. }\end{array}$ \\
\hline $\begin{array}{l}\text { Valinejad and Rahmani } \\
\qquad \text { (2018) }\end{array}$ & $\begin{array}{l}\text { The paper proposes a comprehensive framework to manage sustainability risks in } \\
\text { telecommunication supply chain. }\end{array}$ \\
\hline $\begin{array}{l}\text { Busse, Schleper, } \\
\text { Weilenmann and } \\
\text { Wagner (2017) }\end{array}$ & $\begin{array}{l}\text { The study explores the role of stakeholder network in the identification of the most } \\
\text { salient supply chain sustainability risks. }\end{array}$ \\
\hline $\begin{array}{c}\text { Torres-Ruiz and } \\
\text { Ravindaram (2018) }\end{array}$ & $\begin{array}{l}\text { The study proposes a supply sustainability risk assessment framework to analyze the } \\
\text { potential risks to the sustainability of the supply chain for different supplier segments. }\end{array}$ \\
\hline $\begin{array}{l}\text { Shafiq, Johnson, } \\
\text { Klassen and Awaysheh } \\
\text { (2017) }\end{array}$ & $\begin{array}{l}\text { Based on the agency theory, the study examines the relationship between perceived } \\
\text { sustainability risks and supplier sustainability monitoring practices. }\end{array}$ \\
\hline Busse et al. (2016) & $\begin{array}{l}\text { The paper examines the influence of institutional distance between a supplier's and a } \\
\text { buyer's legitimacy contexts on the paradoxical manifestations of supply chain } \\
\text { sustainability risks using stakeholder and institutional theories. }\end{array}$ \\
\hline $\begin{array}{l}\text { Harclerode, Macbeth, } \\
\text { Miller, Gurr and Myers } \\
\qquad(2016)\end{array}$ & $\begin{array}{l}\text { An early decision framework is developed to facilitate the incorporation of sustainability } \\
\text { risk management practices early in a project life cycle. }\end{array}$ \\
\hline
\end{tabular}




\begin{tabular}{|c|l|}
\hline $\begin{array}{c}\text { Anand, Khan and Wani } \\
\text { (2016) }\end{array}$ & $\begin{array}{l}\text { The paper proposes a sustainability risk assessment index to analyze a mechanical } \\
\text { system at conceptual design stage considering sustainability risks. }\end{array}$ \\
\hline $\begin{array}{c}\text { Anderson and } \\
\text { Anderson (2009) }\end{array}$ & $\begin{array}{l}\text { The study provides a detailed understanding of sustainability risks in general and } \\
\text { describes the need to include sustainability risk management as a part of enterprise risk } \\
\text { management. }\end{array}$ \\
\hline
\end{tabular}

Sustainability risks disrupt the socio-economic-environmental efficiency of freight operations and act as impediments in the development of SFTSs (Giannakis \& Papadopoulos, 2016). A SFTS may be defined as a transportation system that : a) is energy efficient and cost effective; b) maintains the quality and health of the ecosystem by averting accidents, reducing noise, optimizing land use and facilitating people mobility; c) keeps emissions and waste to the minimum; and d) utilizes resources optimally considering the needs of future generation (Goldman \& Gorham, 2006; Lindholm, 2010). It is essential to understand and analyze sustainability risks inherent in SFTSs to ensure timely transfer of the right quantity and quality of shipments with minimum adverse impacts on the society (Shankar et al., 2018). Accordingly, based on the risk management maturity model (Fig. 1), this study proposes a holistic framework in Fig. 3 illustrating the various steps to manage sustainability risks in FTSs.

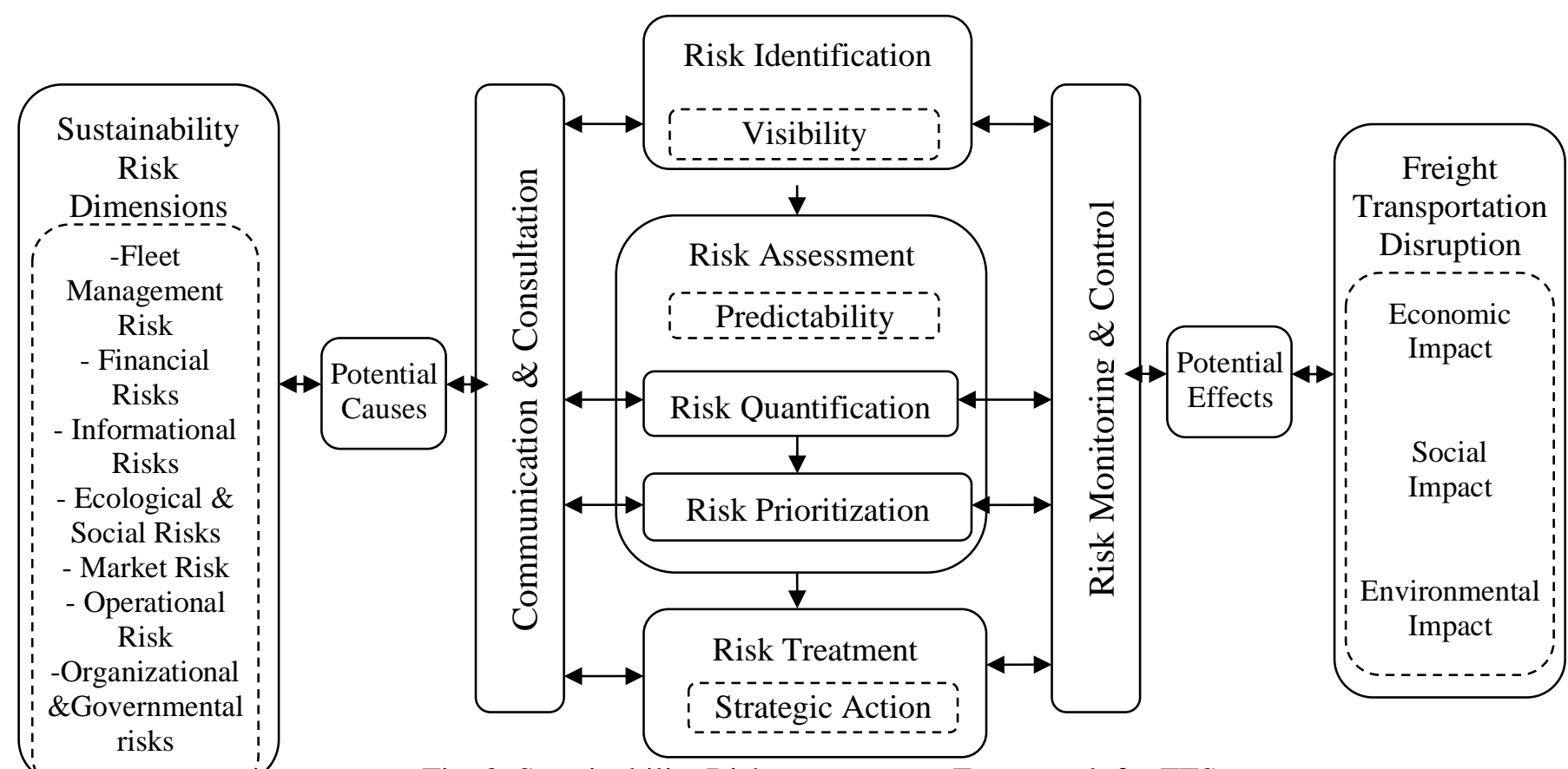

Fig. 3. Sustainability Risk management Framework for FTSs

Organizations should incorporate the risk management practices (Fig. 3) in their FT to avoid the adverse consequences and accomplish the desired goals of SFTSs. Accordingly, a comprehensive list of 36 potential 
sustainability risks associated with FT are identified and categorized as shown in Table II. The detailed explanation of identified sustainability risks is presented in the APPENDIX in Table A1.

Table II: Sustainability Risks in FTSs

\begin{tabular}{|c|c|c|c|}
\hline S.NO. & Risk Categories & Sustainability Risks & References \\
\hline \multirow{4}{*}{1.} & \multirow{4}{*}{$\begin{array}{l}\text { Fleet Management } \\
\text { Risks (FM) }\end{array}$} & Vehicle Utilization Risk (R1) & $\begin{array}{l}\text { Stank and Goldsby (2000); Piecyk and } \\
\text { Mckinnon (2010) }\end{array}$ \\
\hline & & Insufficient Vehicle Range (R2) & SteadieSeifi et al. (2014) \\
\hline & & Fleet Capacity Risk (R3) & Piecyk and Mckinnon (2010) \\
\hline & & Empty Running Risk (R4) & $\begin{array}{l}\text { Goldman and Gorham (2006); Rodrigues et } \\
\text { al (2010); SteadieSeifi et al. (2014) }\end{array}$ \\
\hline \multirow{4}{*}{2.} & \multirow{4}{*}{ Financial Risks (FI) } & Capital Sourcing Risks (R5) & Lindholm (2010) \\
\hline & & Financial Breakdown (R6) & Mangla et al. (2015) \\
\hline & & Fuel Price Volatility (R7) & Richardson (2005); Carter and Rogers (2008) \\
\hline & & Macro Risk (R8) & $\begin{array}{l}\text { Piecyk and Mckinnon (2010); Govindan and } \\
\text { Chaudhuri (2016) }\end{array}$ \\
\hline \multirow{3}{*}{3.} & \multirow{3}{*}{$\begin{array}{l}\text { Informational Risks } \\
\text { (IN) }\end{array}$} & Outbound \& Inbound Logistics Disintegration (R9) & $\begin{array}{l}\text { Stank and Goldsby (2000); Rodrigues et al. } \\
(2010)\end{array}$ \\
\hline & & ICT inadequacy Risk (R10) & $\begin{array}{l}\text { Wang, Rodrigues \& Evans (2015); Rodrigues } \\
\text { and Evans (2015) }\end{array}$ \\
\hline & & Information Dissemination Risk (R11) & Govindan and Chaudhuri (2016) \\
\hline \multirow{8}{*}{4.} & \multirow{8}{*}{$\begin{array}{l}\text { Ecological \& Social } \\
\quad \text { Risks (E\&S) }\end{array}$} & Global Warming risk (R12) & $\begin{array}{l}\text { Gan (2003); Giannakis and Papadopoulos } \\
(2016)\end{array}$ \\
\hline & & Unpredictable Traffic Congestions (R13) & $\begin{array}{l}\text { Goldman and Gorham (2006); Cui et al } \\
\text { (2015); Velazquez et al. (2015) }\end{array}$ \\
\hline & & Escalating Rate of Pollution (R14) & $\begin{array}{l}\text { Piecyk and Mckinnon (2010); Cui et al. } \\
(2015)\end{array}$ \\
\hline & & Visual Intrusion \& Habitat Fragmentation (R15) & $\begin{array}{l}\text { Gan (2003); Demir, Huang, Scholts and } \\
\begin{array}{l}\text { Woensel (2015); Goldman and Gorham } \\
(2006)\end{array}\end{array}$ \\
\hline & & Safety \& Health Risk (R16) & Cui et al. (2015); Velazquez et al. (2015) \\
\hline & & Weather Disruptions (R17) & Demir et al. (2015) \\
\hline & & Workforce Exploitation (R18) & $\begin{array}{l}\text { Carter and Rogers (2008); Giannakis and } \\
\text { Papadopoulos (2016) }\end{array}$ \\
\hline & & Corruption (R19) & Expert opinion \\
\hline \multirow{4}{*}{5.} & \multirow{4}{*}{ Market Risks (MR) } & Demand Volatility (R20) & Srivastava (2006) \\
\hline & & Green Image Risk (R21) & $\begin{array}{l}\text { Carter and Rogers (2008); Mangla et al. } \\
(2015)\end{array}$ \\
\hline & & Geographical Demand Imbalance (R22) & Richardson (2005) \\
\hline & & Market Dynamics (R23) & Expert Opinion \\
\hline \multirow{8}{*}{6.} & \multirow{8}{*}{$\begin{array}{l}\text { Operational Risks } \\
\qquad(\mathrm{OP})\end{array}$} & Delay Risk(R24) & Rodrigues et al (2010); Demir et al. (2015) \\
\hline & & Vehicle Routing \& Scheduling Risk (R25) & $\begin{array}{l}\text { Piecyk and Mckinnon (2010); Velazquez et } \\
\text { al. (2015) }\end{array}$ \\
\hline & & Material Handling Risk (R26) & Expert Opinion \\
\hline & & Driver Associated Risk (R27) & $\begin{array}{l}\text { Richardson (2005); Dubey and Gunasekaran } \\
(2015)\end{array}$ \\
\hline & & Reverse Logistics Risks (R28) & $\begin{array}{l}\text { Ravi and Shankar (2004); Rodrigues et al. } \\
(2010)\end{array}$ \\
\hline & & Non-Standard Orders (R29) & Richardson (2005); Marchet et al. (2014) \\
\hline & & Product Design \& Packaging Inefficacy(R30) & $\begin{array}{l}\text { Richardson (2005); Piecyk and Mckinnon } \\
(2010)\end{array}$ \\
\hline & & Delivery Restrictions Associated Risk (R31) & Rodrigues et al. (2010) \\
\hline \multirow[b]{2}{*}{7.} & \multirow{2}{*}{$\begin{array}{c}\text { Organizational \& } \\
\text { Governmental Risks } \\
(\mathrm{O} \& \mathrm{G})\end{array}$} & Infrastructure \& Technological Bottleneck (R32) & Srivastava (2006); Lindholm (2010) \\
\hline & & $\begin{array}{l}\text { Lack of Management Commitment and Strategic } \\
\text { Competence (R33) }\end{array}$ & $\begin{array}{l}\text { Ravi and Shankar (2004), Carter and Rogers } \\
(2008)\end{array}$ \\
\hline
\end{tabular}




\begin{tabular}{|l|l|c|l|}
\hline \multirow{2}{*}{} & Lack of Awareness \& Logistics Skills (R34) & Lindholm (2010); Marchet et al. (2014) \\
\cline { 3 - 4 } & Unaligned goals of carrier and shipper (R35) & Stank and Goldsby (2000) \\
\cline { 2 - 4 } & Sustainable Regulation Compliance Risk (R36) & $\begin{array}{l}\text { Gan (2003); Marchet et al (2014); Mangla et } \\
\text { al. (2015) }\end{array}$ \\
\hline
\end{tabular}

In accordance with the framework (Fig. 3), the next step involves evaluation and quantification of identified sustainability risks to determine the most critical threats. This exercise can help organizations in proper allocation of resources to mitigate and control risks.

\section{AN INTEGRATED METHOD USING FERA AND EXPECTED UTILITY THEORY (EUT)}

The assessment of sustainability risks in FTSs is an intricate and difficult process due to the highly unpredictable and ambiguous environment (Rodrigues et al., 2010). The study proposes a flexible and robust technique, FERA, by combining the fuzzy set theory (FST) and an evidential reasoning algorithm (ERA) to quantitatively model and analyze the sustainability risks. EUT has been used in an innovative manner to obtain crisp risk priority scores. Fig. 4 presents a step by step methodology used for this research.

\subsection{Linguistic Assessment of Sustainability Risks}

Risk issues are mostly evaluated across two dimensions, namely probability of occurrence $(\mathrm{P})$ and impact (I) (Heckmann, Comes \& Nickel, 2015). The impact of sustainability risks on FTSs has been examined across three dimensions: economic impact (ECI); environmental impact (ENI); and social impact (SI). Subsequently, the severity of sustainability risks is determined by calculating the risk priority level (L) using the following equation (Schlegel \& Trent, 2015).

$$
\mathrm{L}=\mathrm{P} \times \mathrm{I}
$$

Where, $\mathrm{P}$ is the probability of occurrence, $\mathrm{I}$ is the impact and $\mathrm{x}$ represents the multiplication relationship.

This definition also implies that $\mathrm{L}$ will be a fuzzy number if P and I are depicted as fuzzy numbers.

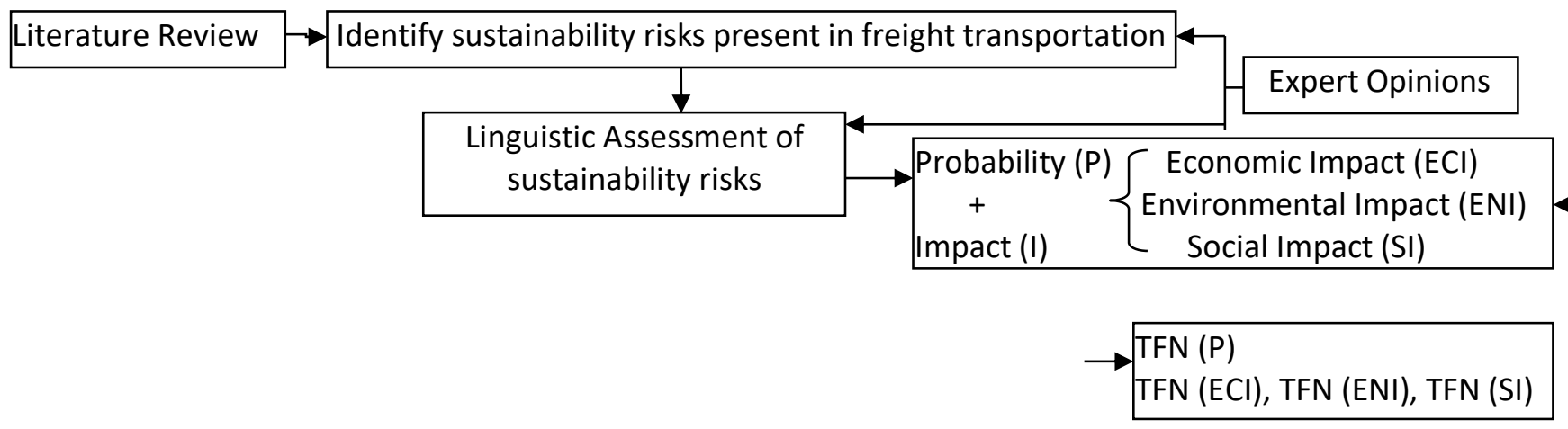




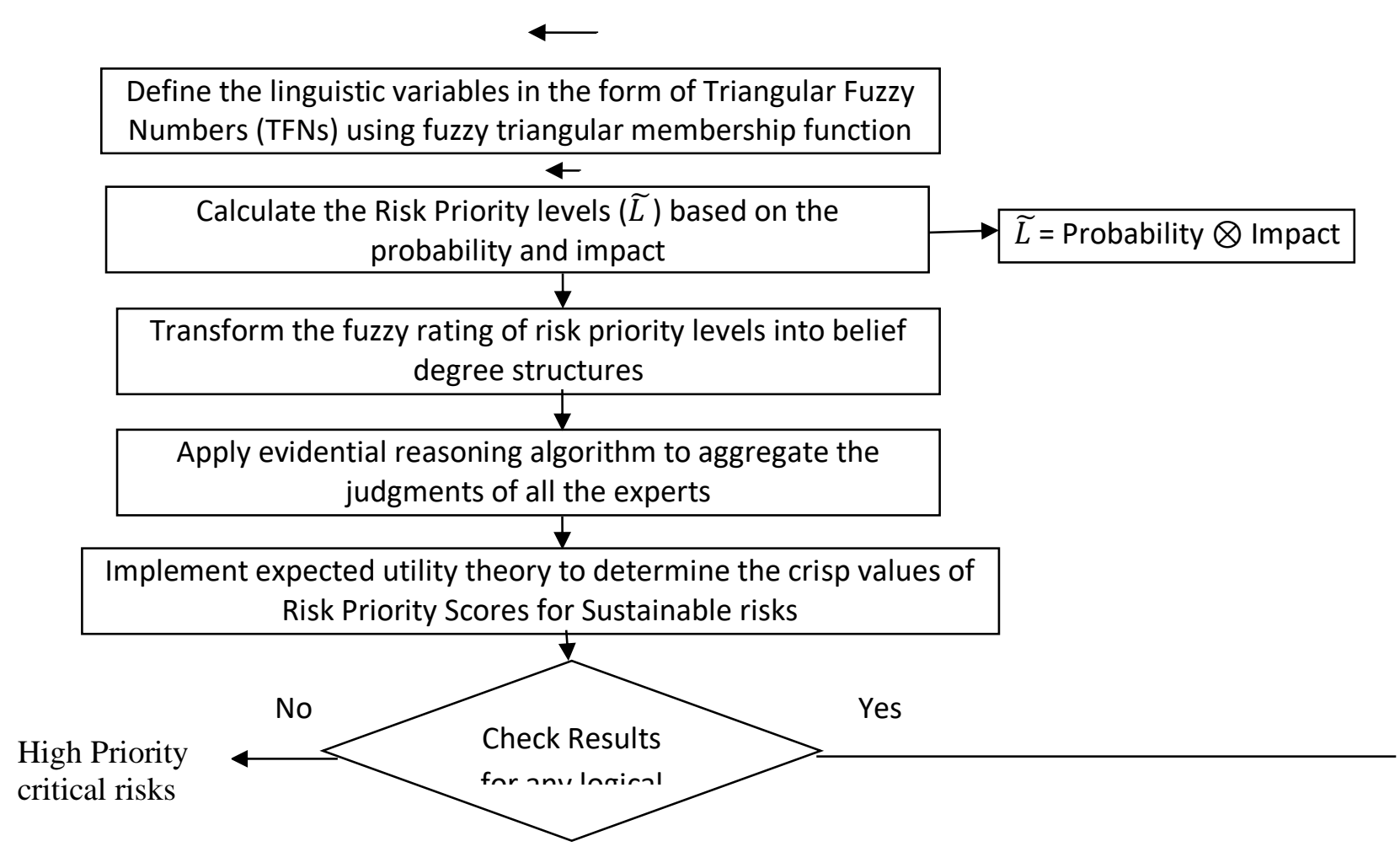

Fig. 4: Step by Step Explanation of Proposed Methodology

\subsection{Application of FST for Risk Evaluation}

FST deals in a group of entities with a continuum of membership grades known as fuzzy sets (Zadeh, 1965). Fuzzy sets may be considered as an extension of crisp sets as they permit partial membership, whereas crisp sets permit either full-membership or non-membership (Chen et al., 2014). The FST concepts are utilized to quantify the linguistic opinions provided by experts (Liu et al, 2011). For this study, a fuzzy membership function based on a five-point scale adapted from John et al. (2014) is employed to transform the linguistic assessment of sustainability risks into triangular fuzzy numbers (TFNs) with a uniform distribution (Table III, Fig. 5).

Table III: Transformation of Linguistic Variables to Fuzzy Triangular Membership Functions

\begin{tabular}{|c|c|c|c|c|c|}
\hline Scale & Probability (P) & $\begin{array}{c}\text { Environmental } \\
\text { Impact (ENI) }\end{array}$ & $\begin{array}{c}\text { Economic Impact } \\
\text { (ECI) }\end{array}$ & $\begin{array}{c}\text { Social Impact } \\
\text { (SI) }\end{array}$ & $\begin{array}{c}\text { Membership } \\
\text { Function }\end{array}$ \\
\hline 1 & Very Low (VL) & Very Low (VL) & Very Low (VL) & Very Low (VL) & $(0.00,0.00,0.25)$ \\
\hline
\end{tabular}




\begin{tabular}{|c|c|c|c|c|c|}
\hline 2 & Low $(\mathrm{L})$ & Low $(\mathrm{L})$ & Low $(\mathrm{L})$ & Low $(\mathrm{L})$ & $(0.00,0.25,0.50)$ \\
\hline 3 & Medium $(\mathrm{M})$ & Medium $(\mathrm{M})$ & Medium $(\mathrm{M})$ & Medium $(\mathrm{M})$ & $(0.25,0.50,0.75)$ \\
\hline 4 & High $(\mathrm{H})$ & $\operatorname{High}(\mathrm{H})$ & $\operatorname{High}(\mathrm{H})$ & $\operatorname{High}(\mathrm{H})$ & $(0.50,0.75,1.00)$ \\
\hline 5 & Very High $(\mathrm{VH})$ & Very High $(\mathrm{VH})$ & Very High $(\mathrm{VH})$ & Very High $(\mathrm{VH})$ & $(0.75,100,1.00)$ \\
\hline
\end{tabular}

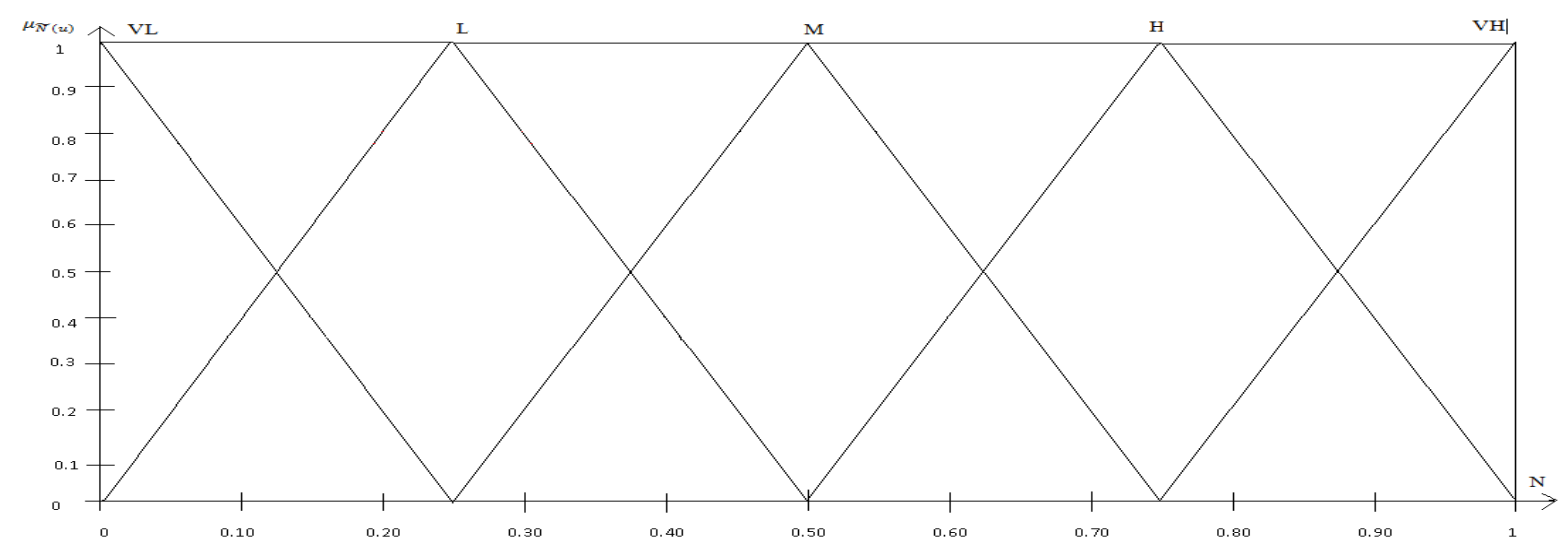

Fig. 5. Fuzzy Triangular Membership Function (Yang, 2001)

Based on Equation1, risk priority level $\left(\mathrm{TFN}_{(\mathrm{PI})}\right)$ can be calculated using triangular fuzzy probability, $\widetilde{P}=$ $\operatorname{TFN}_{(\mathrm{P})}=\left(x_{P}, y_{P}, z_{P}\right)$ and triangular fuzzy impact, $\widetilde{I}=\mathrm{TFN}_{(\mathrm{I})}=\left(x_{I}, y_{I}, z_{I}\right)$ as shown below in Equation 2. Fuzzy impact $\left(\mathrm{TFN}_{(\mathrm{I})}\right)$ can be calculated on the basis of $\widetilde{E C I}=\mathrm{TFN}_{(\mathrm{ECI})}=\left(x_{E C I}, y_{E C I}, z_{E C I}\right), \widetilde{E N I} I=\mathrm{TFN}_{(\mathrm{ENI})}=$ $\left(x_{E N I}, y_{E N I}, z_{E N I}\right)$ and $\widetilde{S I}=\mathrm{TFN}_{(\mathrm{SI})}=\left(x_{S I}, y_{S I}, z_{S I}\right)$ as shown in Equation 3.

$$
\operatorname{TFN}_{(\mathrm{PI})}=\operatorname{TFN}_{(\mathrm{P})} \otimes \operatorname{TFN}_{(\mathrm{I})}=\left(x_{P} * x_{I}, y_{P} * y_{I}, z_{P} * z_{I}\right)
$$

Where,

$\mathrm{TFN}_{(\mathrm{I})}=\operatorname{Avg} .\left(\mathrm{TFN}_{(\mathrm{ECI})}+\mathrm{TFN}_{(\mathrm{ENI})}+\mathrm{TFN}_{(\mathrm{SI})}\right)=\left(\frac{x_{E C I}+x_{E N I}+x_{S I}}{3}, \frac{y_{E C I}+y_{E N I}+y_{S I}}{3}, \frac{z_{E C I}+z_{E N I}+z_{S I}}{3}\right)$

Based on the computed values of risk priority levels $\left(\mathrm{TFN}_{(\mathrm{PI})}\right)$, the FST can categorize the sustainability risks (VL, L, M, H, VH) using the centroid value, $\mathrm{K}$, as shown in Table IV. The centroid value, $\mathrm{K}$, is determined as follows (Zadeh, 1965):

$$
\mathrm{K}=\frac{1}{3}(x+y+z)
$$

Table IV: Description of Qualitative Scale Used for Risk Analysis Based on TFNs

\begin{tabular}{|c|c|c|c|c|}
\hline \multirow{2}{*}{ Qualitative Scalefor sustainability risk analysis } & \multicolumn{2}{|l|}{ Description of evaluation variables } & Risk Priority Level & $\begin{array}{c}\text { Centroid } \\
\text { Values } \\
(\mathrm{K})\end{array}$ \\
\cline { 2 - 3 } & Probability & Impact & Ris \\
\hline
\end{tabular}




\begin{tabular}{|l|c|c|c|c|}
\hline Very Low (VL): Acceptable risk & $\begin{array}{c}\mathrm{VL} \\
(0.00,0.00,0.25)\end{array}$ & $\begin{array}{c}\mathrm{VL} \\
(0.00,0.00,0.25)\end{array}$ & $(0.0,0.0,0.0625)$ & 0.020 \\
\hline $\begin{array}{l}\text { Low (L): Tolerable risk but should be reduced if } \\
\text { feasible. }\end{array}$ & $\begin{array}{c}\mathrm{L} \\
(0.00,0.25,0.50)\end{array}$ & $\begin{array}{c}\mathrm{L} \\
(0.00,0.25,0.50)\end{array}$ & $(0.00,0.0625,0.25)$ & 0.104 \\
\hline $\begin{array}{l}\text { Medium (M): Significant risk that should be } \\
\text { reduced considering cost involved. }\end{array}$ & $\begin{array}{c}\mathrm{M} \\
(0.25,0.50,0.75)\end{array}$ & $\begin{array}{c}\mathrm{M} \\
(0.25,0.50,0.75)\end{array}$ & $(0.0625,0.25,0.5625)$ & 0.292 \\
\hline High (H): Severe risk that must be reduced. & $\begin{array}{c}\mathrm{H} \\
(0.50,0.75,1.00)\end{array}$ & $\begin{array}{c}\mathrm{H} \\
(0.50,0.75,0.10)\end{array}$ & $(0.25,0.5625,1.00)$ & 0.604 \\
\hline $\begin{array}{l}\text { Very High (VH): Highly severe risk, which must } \\
\text { be reduced and controlled immediately. }\end{array}$ & $\begin{array}{c}\mathrm{VH} \\
(0.75,100,1.00)\end{array}$ & $\begin{array}{c}\mathrm{VH} \\
(0.75,100,1.00)\end{array}$ & $(0.5625,1.00,1.00)$ & 0.854 \\
\hline
\end{tabular}

Furthermore, the calculated risk priority levels $\left(\mathrm{TFN}_{(\mathrm{PI})} \mathrm{S}\right)$ need to be transformed into corresponding belief degree structures to provide an input to the ER approach as discussed in the next section.

\subsection{Transformation of $\mathrm{TFN}_{(\mathrm{PI})}$ S into Belief Degree Structures}

A belief degree is the measure of potency to which a judgment is believed to be true (Wang, Yang \& $\mathrm{Xu}$, 2006). The qualitative assessments provided by experts are not a compatible input to ERA for computational analysis. Hence, it is required to convert the fuzzy ratings of risk priority levels, $\mathrm{TFN}_{(\mathrm{PI})}$ into corresponding belief degree structures having the similar set of evaluation grades (Liu et al., 2011). The value of a belief degree is assessed as exactly $100 \%$ or less. The following set of evaluation grades are used to assess the risk priority levels of sustainability risks in FTSs:

$$
\begin{aligned}
R & =\left\{R_{1}, R_{2}, R_{3}, R_{4}, R_{5}\right\} \\
& =\{\text { Very Low, Low, Medium, High, Very High }\}
\end{aligned}
$$

For illustration purposes, if in accordance with Table IV, probability, $\mathrm{P}=$ Medium $(0.25,0.50,0.75)$, economic impact, $\mathrm{ECI}=\operatorname{High}(0.50,0.75,1.00)$, environment impact, ENI $=$ Very High $(0.75,1.00,1.00)$ and social impact, $\mathrm{SI}=\operatorname{Low}(0,0.25,0.50)$ then based on Equation 3 and Equation 2, Impact = $(0.417,0.667,0.834)$ and $\mathrm{TFN}_{(\mathrm{PI})}=(0.104,0.333,0.625)$. Furthermore, in order to transform the $\mathrm{TFN}_{(\mathrm{PI})}$ into fuzzy risk, R, defined in 5 linguistic terms constituting a normalized fuzzy set, i.e., belief structure, the following steps are suggested:

- The computed $\mathrm{TFN}_{(\mathrm{PI})}$ should be mapped over $\mathrm{TFN}_{(\mathrm{L})}$, which has 5 grades (VL, L, M, H and VH) based on Fig. 5. The triangle obtained by the mapping of $\mathrm{TFN}_{(\mathrm{PI})}$ is marked by thick lines as shown in Fig. 6. 
- The points where the newly mapped triangle representing $\mathrm{TFN}_{(\mathrm{PI})}$ intersects each linguistic term of $\operatorname{TFN}_{(\mathrm{L})}$ is identified and marked in Fig. 6.

- If $\mathrm{TFN}_{(\mathrm{PI})}$ triangle intersects a linguistic term of $\mathrm{TFN}_{(\mathrm{L})}$ at more than one point, the maximum value is taken.

- With the help of intersecting points determined in Fig. 6, a fuzzy set, $\mathrm{R}_{\mathrm{L}}$ is established defining 5 non-normalized grades, which are the intersection points of $\mathrm{TFN}_{(\mathrm{PI})}$ and $\mathrm{TFN}_{(\mathrm{L})}$ as shown in Table V.

- $\mathrm{R}_{\mathrm{L}}$ (5 non-normalized grades) is normalized in order to attain $\mathrm{R}$ as shown in Table $\mathrm{V}$.

Table V: Example of Transformation of $\mathrm{TFN}_{(\mathrm{PI})}$ into Belief Structure R

\begin{tabular}{|c|c|c|c|c|c|}
\hline \multicolumn{7}{|c|}{ TFN $_{(\mathrm{PI})}$} & $0.104,0.333,0.625$ \\
\hline Grade & $\mathrm{VL}$ & $\mathrm{L}$ & $\mathrm{M}$ & $\mathrm{H}$ & $\mathrm{VH}$ \\
\hline $\mathrm{R}_{\mathrm{L}}$ & 0.30 & 0.83 & 0.69 & 0.23 & 0.00 \\
\hline $\mathrm{R}$ & 0.146 & 0.405 & 0.337 & 0.112 & 0.000 \\
\hline
\end{tabular}

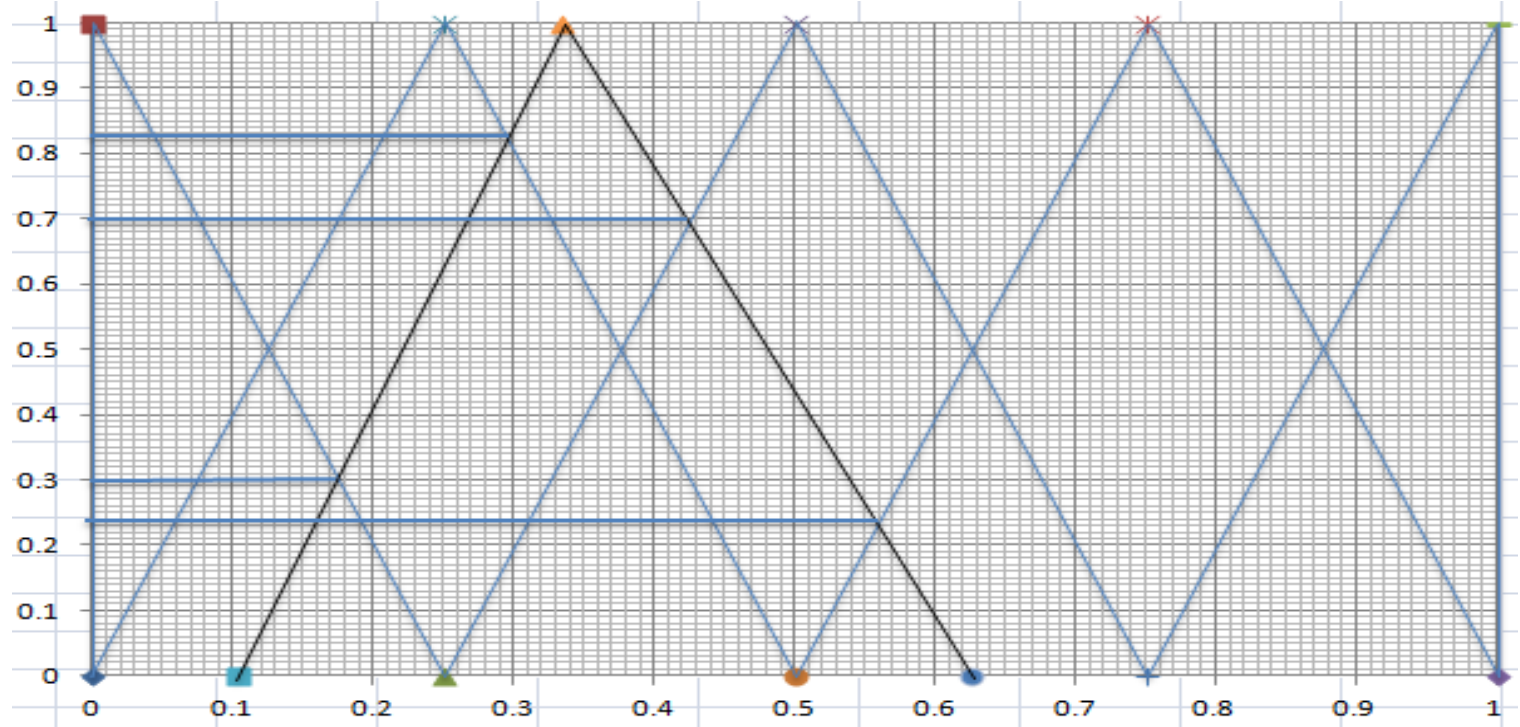

Fig. 6. Example of Transformation of $\mathrm{TFN}_{(\mathrm{PI})}$ into 5 Non- Normalized Grades

The computed belief structures serve as inputs to the ERA approach, which aggregates the belief degrees of experts' judgments to calculate the consolidated risk priority level of sustainability risks (presented in the next section).

\subsection{Application of ERA for Assessment Aggregation}


The ERA approach is developed based on the Dempster-Shafer theory ( D-S theory) of evidence (Shafer, 1976). It has been used to model various multi attribute decision making (MADM) problems with less than precise data and subjective and uncertain information (Chen et al., 2014; Wu et al., 2017). Unlike other techniques, ER methodology implements the evidence combination rule based on the D-S theory to aggregate the degrees of belief from two or more sources instead of synthesizing the average scores across different alternatives (Yang et al., 2009). The ER approach has the capability to handle the subjectivity and high degree of vagueness that no other MADM technique can work with (Liu et al., 2011; Su et al., 2015). This paper employs the ERA to evaluate sustainability risks in FTSs, for the first time, according to the explained pathway proposed by (Yang, 2001).

If $\mathrm{R}$ represents a class of five linguistic risk expressions obtained by the aggregation of two subclasses $\mathrm{R}_{1}$ and $R_{2}$ provided by two different experts, then $R, R_{1}$ and $R_{2}$ can be individually represented by:

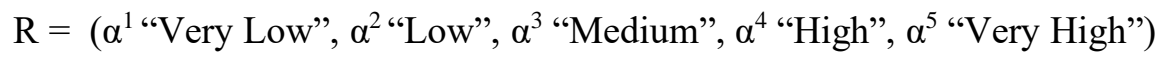

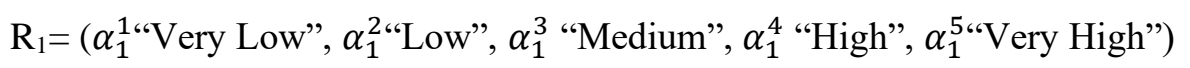

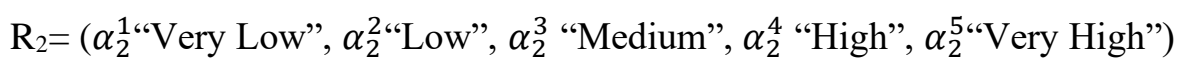

where linguistic expressions are allied with their corresponding belief degrees. Assume $\mathrm{w}_{1}$ and $\mathrm{w}_{2}\left(\mathrm{w}_{1}+\mathrm{w}_{2}\right.$ $=1)$ as the normalized relative weights of two experts involved in the risk evaluation. Further, let $M_{i}^{n}(\mathrm{n}=$ $1,2,3,4$ and $5 ; \mathrm{i}=1$ or 2$)$ represent the degree to which $\mathrm{i}^{\text {th }}$ subset $\left(\mathrm{R}_{\mathrm{i}}\right)$ supports the hypothesis that risk priority level has been assessed to five risk expressions. Then $M_{1}^{n}$ and $M_{2}^{n}$ can be calculated as:

$$
M_{1}^{n}=\mathrm{w}_{1} \times \alpha_{1}^{n} \quad M_{2}^{n}=\mathrm{w}_{2} \times \alpha_{2}^{n}
$$

Suppose $S_{1}$ and $S_{2}$ are the lingering belief degree values unassigned for $M_{1}^{n}$ and $M_{2}^{n}(n=1,2,3,4$ and 5). Then, $S_{1}$ and $S_{2}$ can be obtained as follows (Liu et al., 2011):

$$
\mathrm{S}_{1}=\underline{S}_{1}+\tilde{S}_{1} \quad \mathrm{~S}_{2}=\underline{S}_{2}+\tilde{S}_{2}
$$

where $\underline{S}_{\mathrm{m}}(\mathrm{m}=1$ or 2$)$ corresponds to the degree to which the other expert can have a role in the evaluation, whereas $\tilde{S}_{\mathrm{m}}(\mathrm{m}=1$ or 2$)$ represents the probable incompleteness in the subsets $\mathrm{R}_{1}$ and $\mathrm{R}_{2}$, expressed below: 


$$
\begin{aligned}
& \underline{S}_{1}=1-\mathrm{w}_{1}=\mathrm{w}_{2} \quad \underline{S}_{2}=1-\mathrm{w}_{2}=\mathrm{w}_{1} \\
& \tilde{S}_{1}=\mathrm{w}_{1}\left(1-\sum_{n=1}^{5} \quad \alpha_{1}^{n}\right) \quad \tilde{S}_{2}=\mathrm{w}_{2}\left(1-\sum_{n=1}^{5} \quad \alpha_{2}^{n}\right)
\end{aligned}
$$

Let $\alpha^{n \prime}(\mathrm{n}=1,2,3,4$ and 5) corresponds to the non-normalized degree that evaluation of risks is established to each of the five linguistic risk expressions due to the aggregation of assessments provided by expert 1 and 2. Additionally, suppose that the non-normalized unassigned belief degree remaining after the assignment of belief to the five risk expressions as a result of the aggregation of assessments provided by the expert 1 and 2 is represented by $S_{U}^{\prime}$. Then the recursive ER algorithm can be described as follows (John et al., 2014):

$\alpha^{n \prime}=\mathrm{K}\left(M_{1}^{n} M_{2}^{n}+M_{1}^{n} \mathrm{~S}_{2}+M_{2}^{n} \mathrm{~S}_{1}\right) \quad \underline{S}_{U}^{\prime}=\mathrm{K}\left(\underline{S}_{1} \underline{S}_{2}\right) \quad \tilde{S}_{U}^{\prime}=\mathrm{K}\left(\tilde{S}_{1} \tilde{S}_{2}+\tilde{S}_{1} \mathrm{~S}_{2}+\mathrm{S}_{1} \tilde{S}_{2}\right)$

$\mathrm{K}=\left[1-\sum_{j=1}^{5} \quad \sum_{l=1 l \neq j}^{5} \quad M_{1}^{j} M_{2}^{l}\right]^{-1}$

Lastly, the combined degree of belief, $\alpha^{n}$, generated by the aggregation of assessments provided by the experts for each risk issue and the unassigned belief degree, $\alpha_{U}$ representing the overall incompleteness in evaluation are calculated as follows (Wang et al., 2006):

$\alpha^{n}=\alpha^{n^{\prime}} /\left(1-\underline{S}_{U}^{\prime}\right)(\mathrm{n}=1,2,3,4$ or 5$) \quad \alpha_{U}=\tilde{S}_{U}^{\prime} /\left(1-\underline{S}_{U}^{\prime}\right)$

The aforementioned process corresponds to the combination of two subsets. If more than two subsets are required to be synthesized, then the outcome of aggregation of any two subsets can be combined with the other subset in accordance with the steps described in the algorithm. Similarly, the judgments of various experts can also be combined using this algorithm as illustrated later in the paper.

\subsection{Determination of Equivalent Risk Priority Score via Expected Utility Theory (EUT)}

For the ease of comparison and understanding, the distributed assessment of sustainability risks is transformed to an equivalent numerical value known as risk priority score (RPS) using EUT (John et al., 2014). For computing RPSs, information regarding the utilities of each evaluation grade is required. It is assumed that the utility functions represent the preferences of decision makers (DMs). The three different utility functions according to the proclivity of different experts are shown in Fig. 7 (Wang et al., 2006). 


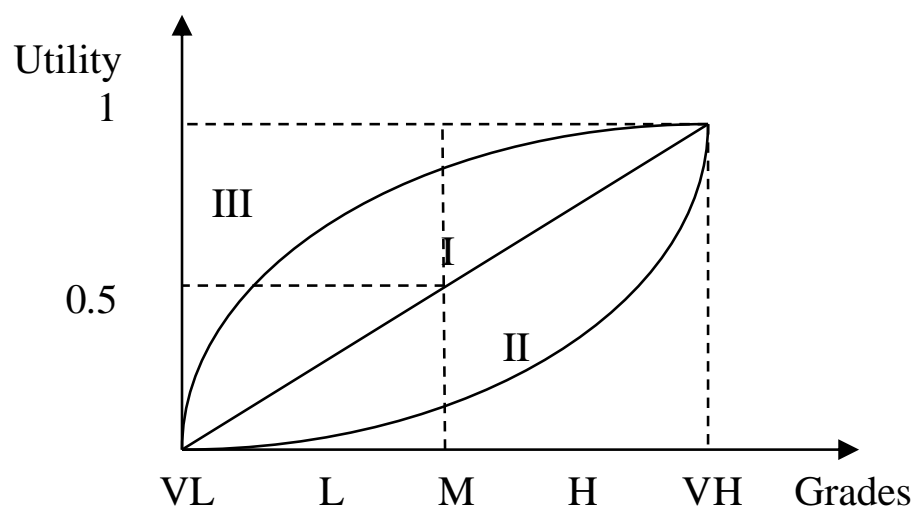

Fig. 7. Utility Functions of Decision Makers

Curve I represents the utility function of a DM with risk- neutral attitude whereas; curve II and curve III represent the risk-taking and risk-averse DMs. In case of risk-neutral DM, it is assumed that the utilities of evaluation terms are equidistantly distributed in the normalized utility space and can be determined as follows (John et al., 2014):

$\mathrm{u}\left(\mathrm{Z}_{\mathrm{n}}\right)=\frac{\left(H_{n}-1\right)}{\left(H_{N}-1\right)}(\mathrm{n}=1,2 \ldots \mathrm{N})$

$H_{n}$ is the rating of the evaluation term under consideration $\left(\mathrm{Z}_{\mathrm{n}}\right)$ and $H_{N}$ is the rating of the most preferred linguistic evaluation grade $\left(\mathrm{Z}_{\mathrm{N}}\right)$. In case of risk-taking and risk-averse DMs, utilities of assessment grades are considered according to DMs preferences. Further, the aggregated distribution assessment of sustainability risks in terms of risk priority level obtained by combining the expert judgments can be represented as:

$\mathrm{S}\left(\mathrm{L}_{\mathrm{i}}\right)=\left\{\left(\mathrm{Z}_{\mathrm{n}}, \alpha_{n}\left(\mathrm{~L}_{\mathrm{i}}\right)\right), \mathrm{n}=1,2,3 \ldots \mathrm{N}\right\}$

Where, $\alpha_{n}$ represents the belief degree that the risk priority level $\mathrm{L}_{\mathrm{i}}$ is assessed to evaluation grade $\mathrm{Z}_{\mathrm{n}}$ and $\alpha_{u}$ denotes the remaining unassigned degree of belief. It has been established that $\sum_{n=1}^{N} \alpha_{n}+\alpha_{u}=$ $1^{(46)}$. If assessment is complete, i.e., $\alpha_{u}=0$, the utility of $\mathrm{S}\left(\mathrm{L}_{\mathrm{i}}\right), \mathrm{u}\left(\mathrm{S}\left(\mathrm{L}_{\mathrm{i}}\right)\right)$ can be determined as follows:

$\mathrm{u}\left(\mathrm{S}\left(\mathrm{L}_{\mathrm{i}}\right)\right)=\sum_{n=1}^{N} \quad \alpha_{n} u(Z n)$

The $\mathrm{u}\left(\mathrm{S}\left(\mathrm{L}_{\mathrm{i}}\right)\right)$ calculated above is the RPS for a particular sustainability risk and is only utilized for characterizing an evaluation but not for aggregation. 


\section{CASE STUDY: APPLICATION OF THE PROPOSED APPROACH IN SUSTAINABILITY RISK ANALYSIS}

This section illustrates the application of the proposed FERA + EUT based model to evaluate the sustainability risks inherent in FT using the Indian context. India is a developing economy and the third largest CO2 emitter in the world after China and United States (WEO, 2015). Most recently India has signed COP21 and there is an urgent need to adopt sustainable practices to curb its emission. Hence, the research aims to facilitate the development of SFTSs in the Indian context.

\subsection{Data Collection}

Focus group sessions are conducted with three expert panels to elicit input for this study due to the lack of statistical data available on sustainability risks. Expert Panels are chosen from the large scale organizations in the logistics sector that are committed to the adoption of green and sustainable practices in their FT operations. The organizations have a turnover of between US\$120-230 million and a fleet size of about 500-1200 high mobility vehicles. Experts are selected considering two major principles: firstly, experts should have a professional experience in one or more areas namely, sustainable decision making, risk management and transportation and must have some knowledge about all the three aspects. Secondly, experts should collectively represent the entire cross section of transportation sector required for analyzing the identified sustainability risks. Appropriate experts within each organization are identified based on their professional responsibilities and appropriate recommendations.

Three focus group sessions are conducted with expert panels involving 12 professionals in total. The panel members have professional experience ranging from five to twenty years and are considered as organizational specialists in the reference domain. Each expert panel involves the logistics head of an organization having extensive experience and knowledge required for the study. The other members include area managers, managers, consultants and analysts working in the area of freight operations, corporate social responsibility, logistics planning, sustainability, risk management and research \& development. These panel members are selected to provide the judgments sought in this research. In focus group sessions, 
initially a description is given about each sustainability risk to provide a basic understanding to all the experts. Next, a questionnaire is provided to all the panel members in which they are asked to linguistically assess the sustainability risks (using the five point scale described in Table III) on the given criteria based on their individual knowledge. Then, the panel members are requested to arrive at a consensus about risk assessments through discussion and a single linguistic assessment of sustainability risks is obtained on the behalf of the entire panel to avoid individual bias. The study evaluates the sustainability risks associated with long distance road FT (> $300 \mathrm{Km}$ ) for $\mathrm{B} 2 \mathrm{~B}$ transactions to achieve targeted and precise results for a specific application. The inputs of the three expert panels have been represented as Expert I, Expert II and Expert III, respectively in the study.

\subsection{Determination of Risk Priority Scores (RPSs)}

On the basis of Fig. 4, RPSs for sustainability risks are determined using FERA and EUT based approach by implementing the following steps:

Step 1: Identification of sustainability risks present in FTSs: In this step, the sustainability risks inherent in FTSs are identified with the help of a rigorous literature review and experts' opinions (Table II).

Step 2: Linguistic assessment of sustainability risk issues: The identified sustainability risks are evaluated by the expert panels based on their probability of occurrence (P) and impact (I), including economic impact (ECI), environmental impact (ENI) and social impact (SI) using linguistic terms (i.e. very low (VL), low (L), medium (M), high (H), very high (VH)) as presented in Table III.

Step 3: Application of FST for evaluating sustainability risks in FTSs: In this step, the linguistic assessments of risk parameters corresponding to P, ECI, ENI and SI are transformed into equivalent TFNs based on Table III followed by the computation of fuzzy impact values (TFN)I for each sustainability risk using Equation 3. Furthermore, fuzzy risk priority level for each sustainability risk is obtained in the form of $(\mathrm{TFN})_{\mathrm{PI}}$ in accordance with Equation 2 and is presented in Table A2 in Appendix.

Step 4: Transformation of $\mathbf{T F N}_{(\mathbf{P I})}$ sinto Belief Degree Structures: This step involves transforming the fuzzy rating of risk priority level (TFN) $)_{\mathrm{PI}}$ into a corresponding belief degree structure by following the steps 
explained in Section 3.3. The intersection results obtained for the sustainability risks are further normalized in accordance with the last step of Section 3.3 and are presented in Table A2 in Appendix.

Step 5: Aggregation of assessments via ERA: The expert panel judgments obtained in the form of belief degrees for each individual sustainability risk are synthesized by applying the ERA as described in Section 3.4 with the help of Equations 5-11. Since the members of all three expert panels have profound knowledge of the concerned area, they are assigned equal weight in the aggregation calculations. The results obtained after ERA calculations are shown in Table VII.

Step 6: Implementation of EUT to obtain a crisp value of RPSs for each sustainability risk: It is more realistic and easier to assess and compare the risks present in a system based on crisp values. Therefore, the expected utility value for each sustainability risk is calculated to obtain its RPS, which corresponds to its priority level in the FTSs. As explained in Section 3.5, if experts are risk-neutral, the utility value of each linguistic grade and a crisp value of RPS for each sustainability risk can be calculated using Equations 1214 (Table VI). Among the set of five linguistic terms used for characterizing the fuzzy risk output, the linguistic grade "Very High" is assigned the highest utility and the lowest priority is assigned to the linguistic term "Very Low". An example to illustrate the computation of RPS is shown in Table VI. It is found that vehicle utilization risk (R1) has a RPS of 0.4201. Furthermore, R1 is categorized as the medium priority risk because the value of its RPS is closer to the centroid value of medium category risks as shown in Table IV. Similarly, the RPSs are obtained for all the identified sustainability risks existing in FTSs and, accordingly, risks are ranked and categorized (Table VII).

Table VI: Crisp Values on Application of Expected Utility Theory

\begin{tabular}{|c|c|c|c|c|c|}
\hline $\mathbf{Z}_{\mathbf{n}}$ & Very Low (VL) & Low $(\mathbf{L})$ & Medium (M) & High (H) & Very High (VH) \\
\hline $\mathbf{H}_{\mathbf{n}}$ & 1 & 2 & 3 & 4 & 5 \\
\hline $\mathbf{u}\left(\mathbf{Z}_{\mathbf{n}}\right)$ & $\frac{1-1}{5-1}=0$ & $\frac{2-1}{5-1}=0.25$ & $\frac{3-1}{5-1}=0.5$ & $\frac{4-1}{5-1}=0.75$ & $\frac{5-1}{5-1}=1$ \\
\hline$\alpha_{n}$ & 0.0902 & 0.3358 & 0.3950 & 0.1617 & 0.0174 \\
\hline$\sum_{n=1}^{5} \alpha_{n}=0.0902+0.3358+0.3950+0.1617+0.0174=1 \underset{\alpha_{u}}{\longrightarrow}=0$ \\
\hline$\alpha_{n} \times \mathbf{u}\left(\mathbf{Z}_{\mathbf{n}}\right)$ & 0 & 0.0841 & 0.1975 & 0.121 & 0.0175 \\
\hline$\sum_{n=1}^{5} \alpha_{n} \times u(Z n)=\mathbf{R P S}_{\mathbf{R} 11}=\mathbf{0 . 4 2 0 1}$ \\
\hline
\end{tabular}

Table VII: Categorization of Sustainability Risks Based on RPSs

\begin{tabular}{|l|c|c|c|c|c|}
\hline Risk Categories & Risks & Aggregated Assessment via ERA $\left(\alpha_{\mathbf{n}}\right)$ & RPS & Rank & Categorization $(C)$ \\
\hline
\end{tabular}




\begin{tabular}{|c|c|c|c|c|c|c|c|c|c|}
\hline & & $\mathbf{V L}$ & $\mathbf{L}$ & $\mathbf{M}$ & $\mathbf{H}$ & VH & & & \\
\hline \multirow{4}{*}{$\begin{array}{l}\text { Fleet Management } \\
\text { Risk }\end{array}$} & R1 & 0.0902 & 0.3358 & 0.3950 & 0.1617 & 0.0174 & 0.4201 & 20 & M \\
\hline & $\mathrm{R} 2$ & 0.2722 & 0.4423 & 0.2331 & 0.0521 & 0 & 0.2663 & 27 & $\mathrm{M}$ \\
\hline & R3 & 0.2844 & 0.4400 & 0.2229 & 0.0521 & 0 & 0.2609 & 28 & $\mathrm{M}$ \\
\hline & $\mathrm{R} 4$ & 0.0220 & 0.1773 & 0.3760 & 0.3231 & 0.1016 & 0.5762 & 8 & $\mathrm{H}$ \\
\hline \multirow{4}{*}{ Financial Risks } & R5 & 0.4006 & 0.4486 & 0.1509 & 0 & 0 & 0.1876 & 33 & $\mathrm{~L}$ \\
\hline & R6 & 0.2927 & 0.5185 & 0.1888 & 0 & 0 & 0.224 & 31 & $\mathrm{M}$ \\
\hline & R7 & 0.1097 & 0.4086 & 0.3537 & 0.1280 & 0 & 0.375 & 24 & $\mathrm{M}$ \\
\hline & $\mathrm{R} 8$ & 0.3917 & 0.4683 & 0.1397 & 0 & 0 & 0.1871 & 34 & $\mathrm{~L}$ \\
\hline \multirow{3}{*}{$\begin{array}{l}\text { Informational } \\
\text { Risks }\end{array}$} & R9 & 0.0509 & 0.2304 & 0.3223 & 0.2816 & 0.1145 & 0.5446 & 10 & $\mathrm{H}$ \\
\hline & R10 & 0.2240 & 0.4086 & 0.2636 & 0.0738 & 0.0301 & 0.3193 & 26 & $\mathrm{M}$ \\
\hline & R11 & 0.3191 & 0.3997 & 0.2133 & 0.0679 & 0 & 0.2575 & 29 & $\mathrm{M}$ \\
\hline \multirow{8}{*}{$\begin{array}{l}\text { Ecological \& } \\
\text { Social Risks }\end{array}$} & $\mathrm{R} 12$ & 0 & 0.1561 & 0.3655 & 0.3349 & 0.1435 & 0.6165 & 5 & $\mathrm{H}$ \\
\hline & R13 & 0.0201 & 0.1097 & 0.2853 & 0.3662 & 0.2184 & 0.6633 & 3 & $\mathrm{H}$ \\
\hline & R14 & 0 & 0.0972 & 0.2913 & 0.3884 & 0.2231 & 0.6844 & 2 & $\mathrm{H}$ \\
\hline & $\mathrm{R} 15$ & 0.1368 & 0.2879 & 0.3054 & 0.1965 & 0.0734 & 0.4454 & 17 & M \\
\hline & R16 & 0 & 0.1554 & 0.3631 & 0.3368 & 0.1443 & 0.6175 & 4 & $\mathrm{H}$ \\
\hline & R17 & 0.4648 & 0.4238 & 0.1114 & 0 & 0 & 0.1616 & 35 & $\mathrm{~L}$ \\
\hline & $\mathrm{R} 18$ & 0.1190 & 0.3724 & 0.3402 & 0.1439 & 0.0244 & 0.3956 & 23 & $\mathrm{M}$ \\
\hline & R19 & 0 & 0.1418 & 0.3606 & 0.4070 & 0.0903 & 0.6114 & 6 & $\mathrm{H}$ \\
\hline \multirow{4}{*}{ Market Risk } & $\mathrm{R} 20$ & 0.0777 & 0.3209 & 0.3682 & 0.1917 & 0.0412 & 0.4494 & 16 & $\mathrm{H}$ \\
\hline & $\mathrm{R} 21$ & 0.5703 & 0.3838 & 0.0459 & 0 & 0 & 0.1189 & 36 & $\mathrm{~L}$ \\
\hline & $\mathrm{R} 22$ & 0.0958 & 0.3526 & 0.3615 & 0.1678 & 0.0219 & 0.4169 & 21 & $\mathrm{M}$ \\
\hline & $\mathrm{R} 23$ & 0.0404 & 0.2297 & 0.3946 & 0.2583 & 0.0764 & 0.5251 & 12 & $\mathrm{H}$ \\
\hline \multirow{8}{*}{ Operational Risks } & $\mathrm{R} 24$ & 0.0644 & 0.2806 & 0.4136 & 0.2070 & 0.0338 & 0.4663 & 14 & $\mathrm{H}$ \\
\hline & $\mathrm{R} 25$ & 0.1133 & 0.3544 & 0.3111 & 0.1651 & 0.0558 & 0.4239 & 19 & $\mathrm{M}$ \\
\hline & $\mathrm{R} 26$ & 0.0753 & 0.2966 & 0.3973 & 0.1975 & 0.0324 & 0.4538 & 15 & $\mathrm{H}$ \\
\hline & $\mathrm{R} 27$ & 0.0087 & 0.1786 & 0.3923 & 0.2997 & 0.1207 & 0.5863 & 7 & $\mathrm{H}$ \\
\hline & $\mathrm{R} 28$ & 0.4084 & 0.3690 & 0.1692 & 0.0528 & 0 & 0.2167 & 32 & $\mathrm{M}$ \\
\hline & $\mathrm{R} 29$ & 0.0557 & 0.2599 & 0.3887 & 0.2366 & 0.0589 & 0.4958 & 13 & $\mathrm{H}$ \\
\hline & $\mathrm{R} 30$ & 0.2762 & 0.5013 & 0.2076 & 0.0149 & 0 & 0.2403 & 30 & M \\
\hline & R31 & 0.1926 & 0.3874 & 0.2931 & 0.1105 & 0.0162 & 0.3426 & 25 & $\mathrm{M}$ \\
\hline \multirow{5}{*}{$\begin{array}{c}\text { Organizational \& } \\
\text { Governmental } \\
\text { Risks }\end{array}$} & $\mathrm{R} 32$ & 0.0435 & 0.2068 & 0.3352 & 0.2946 & 0.1193 & 0.5598 & 9 & $\mathrm{H}$ \\
\hline & R33 & 0.1006 & 0.3043 & 0.3683 & 0.1731 & 0.0537 & 0.4437 & 18 & $\mathrm{M}$ \\
\hline & R34 & 0 & 0.0864 & 0.2777 & 0.4272 & 0.2088 & 0.6896 & 1 & $\mathrm{H}$ \\
\hline & R35 & 0.1023 & 0.3443 & 0.3890 & 0.1638 & 0 & 0.4037 & 22 & $\mathrm{M}$ \\
\hline & R36 & 0.0301 & 0.2079 & 0.3999 & 0.2803 & 0.0815 & 0.5438 & 11 & $\mathrm{H}$ \\
\hline
\end{tabular}

In cases of risk-taking and risk-averse attitudes, the utilities of evaluation terms are taken from the expert panels and are as follows:

Risk-taking DMs $u(\mathrm{VL})=0, u(\mathrm{~L})=0.15, u(\mathrm{M})=0.30, u(\mathrm{H})=0.65, u(\mathrm{VH})=1$.

Risk-averse DMs $u(\mathrm{VL})=0, u(\mathrm{~L})=0.35, u(\mathrm{M})=0.70, u(\mathrm{H})=0.85, u(\mathrm{VH})=1$.

Based on these utility values (Equations 15 and 16), the RPSs, corresponding priority rankings and categories are evaluated again for all the identified risks accounting for the risk-taking and risk-averse preferences. The results obtained for the three risk preferences are compared in Table VIII.

Table VIII: Comparison of Risk-Neutral, Risk-Averse and Risk-Taking Perceptions 


\begin{tabular}{|c|c|c|c|c|c|c|c|c|c|c|}
\hline \multirow[b]{2}{*}{ Risk Categories } & \multirow{2}{*}{ Risks } & \multicolumn{3}{|c|}{ Risk-Neutral } & \multicolumn{3}{|c|}{ Risk-Taking } & \multicolumn{3}{|c|}{ Risk-Averse } \\
\hline & & RPSs & Rank & C & RPSs & Rank & $\mathbf{C}$ & RPSs & Rank & $\mathbf{C}$ \\
\hline \multirow{4}{*}{$\begin{array}{l}\text { Fleet Management } \\
\text { Risk }\end{array}$} & R1 & 0.4201 & 20 & $\mathrm{M}$ & 0.2914 & 21 & $\mathrm{M}$ & 0.5489 & 19 & $\mathrm{H}$ \\
\hline & R2 & 0.2663 & 27 & $\mathrm{M}$ & 0.1701 & 27 & $\mathrm{~L}$ & 0.3623 & 27 & $\mathrm{M}$ \\
\hline & R3 & 0.2609 & 28 & $\mathrm{M}$ & 0.1667 & 29 & $\mathrm{~L}$ & 0.3543 & 28 & $\mathrm{M}$ \\
\hline & $\mathrm{R} 4$ & 0.5762 & 8 & $\mathrm{H}$ & 0.4510 & 8 & $\mathrm{H}$ & 0.7015 & 8 & $\mathrm{H}$ \\
\hline \multirow{4}{*}{ Financial Risks } & R5 & 0.1876 & 33 & $\mathrm{~L}$ & 0.1126 & 33 & $\mathrm{~L}$ & 0.2626 & 33 & $\mathrm{M}$ \\
\hline & R6 & 0.224 & 31 & $\mathrm{M}$ & 0.1344 & 32 & $\mathrm{~L}$ & 0.3136 & 31 & $\mathrm{M}$ \\
\hline & R7 & 0.375 & 24 & $\mathrm{M}$ & 0.2506 & 24 & M & 0.4994 & 24 & $\mathrm{H}$ \\
\hline & R8 & 0.1871 & 34 & $\mathrm{~L}$ & 0.1122 & 34 & $\mathrm{~L}$ & 0.2617 & 34 & $\mathrm{M}$ \\
\hline \multirow{3}{*}{ Informational Risks } & R9 & 0.5446 & 10 & $\mathrm{H}$ & 0.4288 & 10 & M & 0.6601 & 11 & $\mathrm{H}$ \\
\hline & R10 & 0.3193 & 26 & $\mathrm{M}$ & 0.2184 & 26 & $\mathrm{M}$ & 0.4204 & 26 & M \\
\hline & R11 & 0.2575 & 29 & $\mathrm{M}$ & 0.1681 & 28 & $\mathrm{~L}$ & 0.3469 & 29 & M \\
\hline \multirow{8}{*}{\begin{tabular}{|} 
Ecological \& Social \\
Risks
\end{tabular}} & R12 & 0.6165 & 5 & $\mathrm{H}$ & 0.4943 & 5 & $\mathrm{H}$ & 0.7387 & 5 & $\mathrm{VH}$ \\
\hline & R13 & 0.6633 & 3 & $\mathrm{H}$ & 0.5585 & 3 & $\mathrm{H}$ & 0.7678 & 3 & $\mathrm{VH}$ \\
\hline & R14 & 0.6844 & 2 & $\mathrm{H}$ & 0.5775 & 2 & $\mathrm{H}$ & 0.7912 & 2 & $\mathrm{VH}$ \\
\hline & R15 & 0.4454 & 17 & $\mathrm{M}$ & 0.3359 & 14 & $\mathrm{M}$ & 0.5550 & 18 & $\mathrm{H}$ \\
\hline & R16 & 0.6175 & 4 & $\mathrm{H}$ & 0.4955 & 4 & $\mathrm{H}$ & 0.7391 & 4 & $\mathrm{VH}$ \\
\hline & R17 & 0.1616 & 35 & $\mathrm{~L}$ & 0.0970 & 35 & $\mathrm{~L}$ & 0.2263 & 35 & M \\
\hline & R18 & 0.3956 & 23 & $\mathrm{M}$ & 0.2759 & 22 & $\mathrm{M}$ & 0.5152 & 23 & $\mathrm{H}$ \\
\hline & R19 & 0.6114 & 6 & $\mathrm{H}$ & 0.4843 & 6 & $\mathrm{H}$ & 0.7383 & 6 & $\mathrm{VH}$ \\
\hline \multirow{4}{*}{ Market Risk } & R20 & 0.4494 & 16 & $\mathrm{H}$ & 0.3244 & 17 & M & 0.5742 & 16 & $\mathrm{H}$ \\
\hline & R21 & 0.1189 & 36 & $\mathrm{~L}$ & 0.0713 & 36 & $\mathrm{~L}$ & 0.1665 & 36 & $\mathrm{~L}$ \\
\hline & R22 & 0.4169 & 21 & $\mathrm{M}$ & 0.2923 & 20 & $\mathrm{M}$ & 0.5410 & 20 & $\mathrm{H}$ \\
\hline & R23 & 0.5251 & 12 & $\mathrm{H}$ & 0.3971 & 12 & M & 0.6526 & 12 & $\mathrm{H}$ \\
\hline \multirow{8}{*}{ Operational Risks } & R24 & 0.4663 & 14 & $\mathrm{H}$ & 0.3345 & 15 & $\mathrm{M}$ & 0.5975 & 14 & $\mathrm{H}$ \\
\hline & R25 & 0.4239 & 19 & $\mathrm{M}$ & 0.3096 & 19 & M & 0.5379 & 21 & $\mathrm{H}$ \\
\hline & R26 & 0.4538 & 15 & $\mathrm{H}$ & 0.3245 & 16 & $\mathrm{M}$ & 0.5822 & 15 & $\mathrm{H}$ \\
\hline & R27 & 0.5863 & 7 & $\mathrm{H}$ & 0.4600 & 7 & $\mathrm{H}$ & 0.7126 & 7 & $\mathrm{H}$ \\
\hline & R28 & 0.2167 & 32 & $\mathrm{M}$ & 0.1404 & 31 & $\mathrm{~L}$ & 0.2925 & 32 & M \\
\hline & R29 & 0.4958 & 13 & $\mathrm{H}$ & 0.3683 & 13 & $\mathrm{M}$ & 0.6231 & 13 & $\mathrm{H}$ \\
\hline & R30 & 0.2403 & 30 & $\mathrm{M}$ & 0.1472 & 30 & $\mathrm{~L}$ & 0.3334 & 30 & M \\
\hline & R31 & 0.3426 & 25 & $\mathrm{M}$ & 0.2341 & 25 & $\mathrm{M}$ & 0.4509 & 25 & $\mathrm{H}$ \\
\hline \multirow{5}{*}{$\begin{array}{c}\text { Organizational \& } \\
\text { Governmental Risks }\end{array}$} & R32 & 0.5598 & 9 & $\mathrm{H}$ & 0.4424 & 9 & M & 0.6767 & 9 & $\mathrm{H}$ \\
\hline & R33 & 0.4437 & 18 & M & 0.3224 & 18 & M & 0.5652 & 17 & $\mathrm{H}$ \\
\hline & R34 & 0.6896 & 1 & $\mathrm{H}$ & 0.5828 & 1 & $\mathrm{H}$ & 0.7966 & 1 & $\mathrm{VH}$ \\
\hline & R35 & 0.4037 & 22 & $\mathrm{M}$ & 0.2748 & 23 & $\mathrm{M}$ & 0.5320 & 22 & $\mathrm{H}$ \\
\hline & R36 & 0.5438 & 11 & $\mathrm{H}$ & 0.4149 & 11 & M & 0.6725 & 10 & $\mathrm{H}$ \\
\hline
\end{tabular}

The RPSs, corresponding rankings and the equivalent classifications determined for sustainability risks provide ground for enhancing the sustainability performance of FTSs through identification of critical areas that require improvement and control.

\subsection{Results and Discussions}

Managing sustainability in FT requires the mapping of inherent sustainability risks to gain the visibility across SFTSs. An integrated approach based on FERA and EUT has been developed to evaluate and categorize the sustainability risks in FTSs. Results confirm that all the considered risks pose a serious threat 
to SFTSs as none of them is in the very low priority zone in all three scenarios. The priority of sustainability risks for the risk-neutral attitude is graphically depicted in Fig. 8.

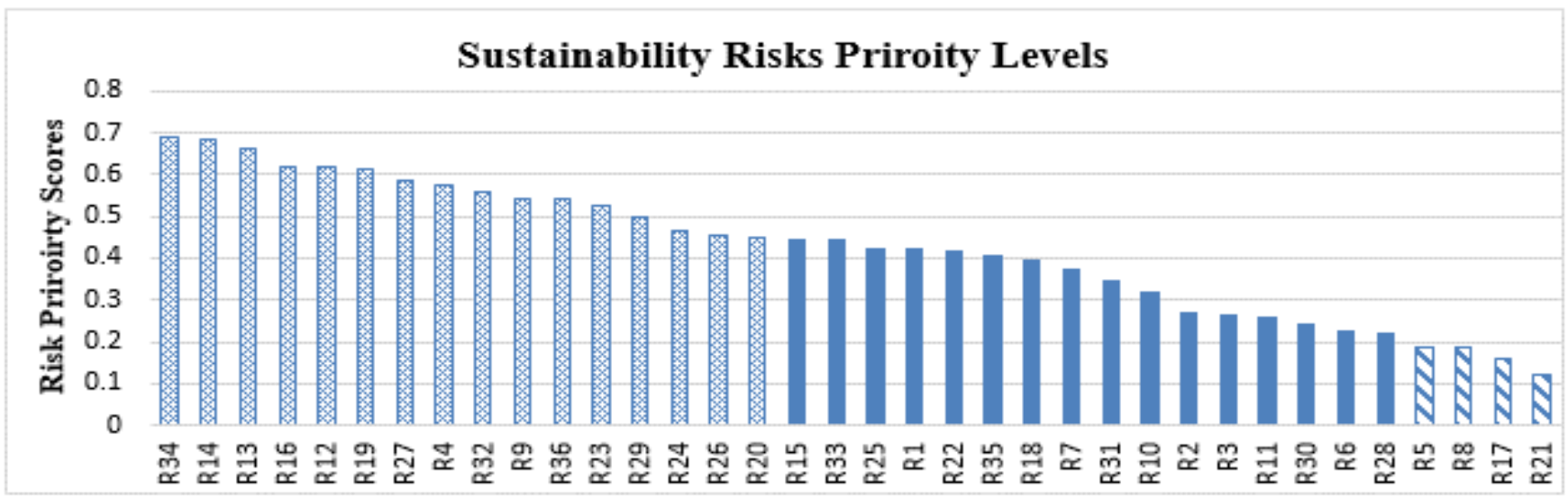

Fig. 8. Priority Order of Sustainability Risks in FTSs

In Fig. 8, the first 16 risks represented in check pattern, namely R34, R14, R13, R16, R12, R19, R27, R4, R32, R9, R36, R23, R29, R24, R26 and R20, are categorized as the high priority sustainability risks (Table VIII). The next 16 sustainability risks (represented in solid pattern) are classified as the medium priority risks. These include R15, R33, R25, R1, R22, R35, R18, R7, R31, R10, R2, R3, R11, R30, R6 and R28 in order of decreasing priority. The last four sustainability risks (represented in diagonal pattern), namely R5, $\mathrm{R} 8, \mathrm{R} 17$ and $\mathrm{R} 21$, are the low priority risks.

Lack of Awareness \& Logistics Skill (R34) in the organizational \& governmental risk category is found to be the highest priority sustainability risk. The finding is in line with the Indian Transport Report (NTDPC, 2014), which acknowledged that the Indian logistics sector is majorly hamstrung due to lack of skills and domain knowledge. This suggests that organizations should seek to develop proficient workforce that can contribute in achieving sustainable freight practices (Ravi \& Shankar, 2004). The priority order of the remaining risks in $\mathrm{O} \& \mathrm{G}$ category is $\mathrm{R} 32>\mathrm{R} 36>\mathrm{R} 33>\mathrm{R} 35 . \mathrm{R} 32$ ( $9^{\text {th }}$ rank) and $\mathrm{R} 36$ ( $11^{\text {th }}$ rank) are the high priority risks resulting due to the uncertainties in technological advancements and non-compliance of laws and both are dependent on R33 to some extent. Srivastava (2006) also indicated that the state of technology and infrastructure in India are not only leading to environmental degradation but also hampering the 
economics of transportation. Organizations are paying huge penalties for the violation of environmental laws leading to R36. In order to address these risks, there is a significant need for government interventions and top-level management commitment (R33) to facilitate the development of innovative technologies and infrastructure and regulation compliance (Gan, 2003; Cavinto, 2004; Goldman \& Gorham, 2006).

In the E\&S risk category, R14, R13, R16, R12 and R19 are the high priority risks occupying $2^{\text {nd }}, 3^{\text {rd }}, 4^{\text {th }}, 5^{\text {th }}$ and $6^{\text {th }}$ positions, respectively, in the priority ranking. In accordance with many studies, rapidly growing air, water and noise pollution, GHG emissions and accidents are among the most severe negative externalities of FT. This is also visible in the resultsthroughR14, R16and R12, which are figuring in the high priority zone. It is corroborated by the fact that many Indian cities have been ranked most polluted in the world and about 154,000 people died in India in 2005 due to traffic-related air pollution (NTDPC, 2014). Furthermore, transportation accounts for about 20,000 accident fatalities and 100,000 premature deaths annually due to the air pollution in the European Union (ERTRAC, 2011). To curb these sustainability risks, immediate actions such as using alternative fuels, vehicle consolidation, carbon footprint optimization, participation in emission reduction initiatives, increased utilization of railways and inter-modal transportation should be implemented (Gan, 2003; SteadieSeifi, 2014; Velazquez et al., 2015; Giannakis \& Papadopoulos, 2016). Exponentially increasing vehicles on the road coupled with poor infrastructure lead to R13, which hugely affect the sustainability of FT and cause driver stress. The availability of real-time traffic information and development of dedicated freight corridors could reduce the likelihood of R13 (Schliwa et al., 2015; Piecyk \& Mckinnon, 2010; Wang et al., 2015). Furthermore, R19 is posing a serious threat to the FT industry in India as it accounts for about few thousand USDs per year per truck (Raghuram, 2016). Stringent government regulation and rigorous organizational efforts are required to control the fraudulent behavior.

In the OP risk category, R27 ( $7^{\text {th }}$ rank), R29 (13 ${ }^{\text {th }}$ rank), R24 (14 ${ }^{\text {th }}$ rank) and R26 $\left(15^{\text {th }}\right)$ are categorized as the high priority risks whereas the remaining four risks, $\mathrm{R} 25>\mathrm{R} 31>\mathrm{R} 30>\mathrm{R} 28$, have the medium priority. 
Drivers are key players in FTSs and their skill gaps or behavioral issues result in R27. Dubey and Gunasekaran (2015) also suggested that poor social and skill sets, lack of sensitivity towards environment and inadequate awareness in drivers are the primary contributors of the unsustainable Indian freight sector. Managers are advised to set structured hiring standards and provide insurances, fair working hours, regular training and reward programs for drivers to address R27 (Schliwa et al., 2015; Dubey \& Gunasekaran, 2015). Disparate customer demands and the movement towards customized solutions result in R29. Furthermore, R24 leads to poor load factor running and thus necessitates extra trips to handle missed loads, which result in higher transportation costs and emissions. Rodrigues et al. (2010) also identified delays as one of the four prominent areas responsible for uncertainties in SFTSs. Optimally designed FT routes and real-time tracking resulting in on-time delivery improvements can mitigate R24 (Wang et al., 2015). R26 can be reduced by following suitable packaging and proper loading and unloading strategies.

The priority ranking in market risk category is R23>R20>R22>R21 withR23 (12 ${ }^{\text {th }}$ position) and R20 (16 ${ }^{\text {th }}$ position) categorized as the high priority sustainability risks. Customers' and stakeholders' reluctance to bear the cost of sustainability leads to R23. Hence, raising awareness and education is essential to bring a positive change in people's perceptions. R20 mainly arises due to insufficient visibility and lack of accurate demand forecasting (SteadieSeifi et al., 2014). R21 is ranked last in this category and in the overall ranking possibly as most organizations include sustainability principles in their business portfolio to improve brand image and are extremely conscious about upholding it. The remaining two high priority sustainability risks, $\mathrm{R} 4\left(8^{\text {th }}\right.$ rank) and R9 ( $10^{\text {th }}$ rank), belong to the fleet management and informational risk categories respectively. In India, 30-50\% of truck-loads return empty due to regional haulers leading to R4 (Avendus, 2016). An intelligent transportation system facilitates real-time information sharing and integration of transportation vehicles, which may reduce the prospects of R4 and R9 (Gan, 2003; SteadieSeifi et al., 2014; Velazquez et al., 2015).In one of the cases, use of ICT reduced the empty running (R4) by 12 percent resulting in $\mathrm{CO}_{2}$ reductions by 1.4 million kilograms in a year (Wang et al., 2015). Furthermore, none of the sustainability risks in the financial category $(\mathrm{R} 7>\mathrm{R} 6>\mathrm{R} 5>\mathrm{R} 8)$ is a high priority risk. Nevertheless, it is 
important to note that the majority of high priority sustainability risks may indirectly disrupt the economic sustainability of FTSs.

The categorization of sustainability risks discussed above is based on the risk-neutral perspective (Table VII). For risk-taking and risk-averse behaviors, the priority rankings of sustainability risks are presented in Figs. 9 and 10 (Table VIII).

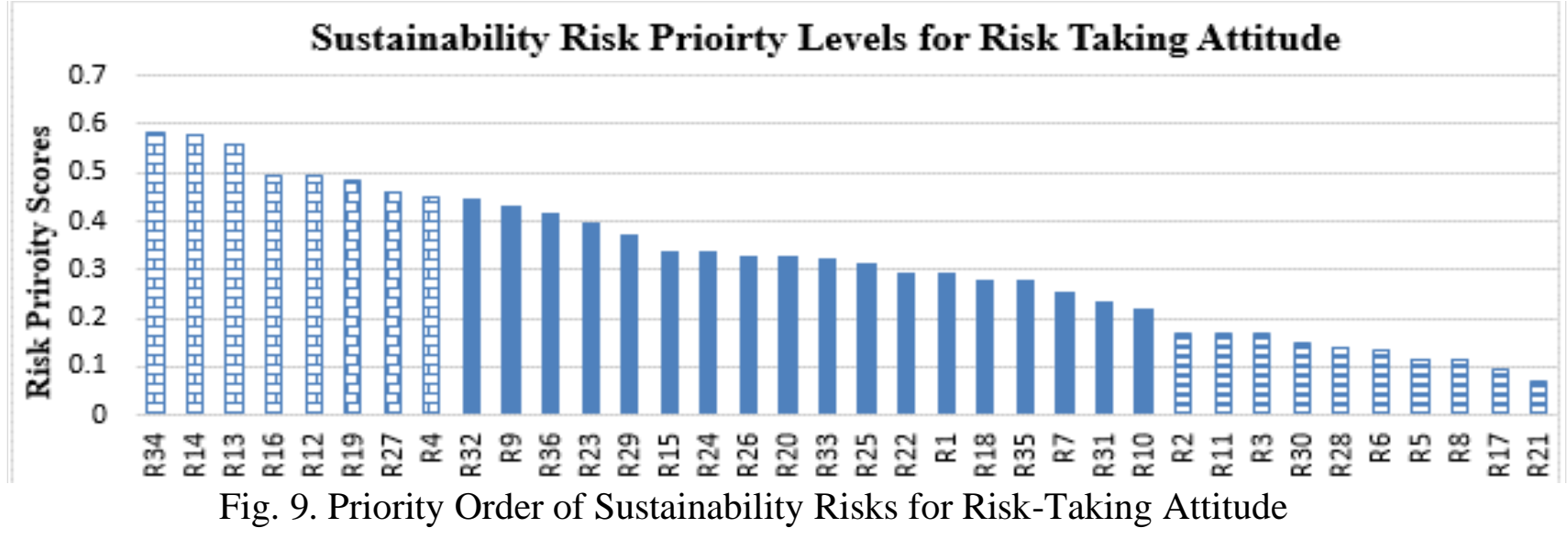

It can be observed that the top nine ranked sustainability risks are the same in all three cases (risk-neutral, risk-taking and risk-averse perspectives), whereas slight differences exist in the ranking of remaining risks. For the risk-taking approach, the RPSs are slightly reduced and only eight risks (brick pattern), namely R34, R14, R13, R16, R12, R19, R27 and R4, are classified as high priority risks as compared to sixteen in case of risk-neutral attitude. Eighteen sustainability risks (solid pattern) are in the medium priority category and the remaining ten fell into the low priority group (horizontal pattern) (Fig. 8). For the risk-averse perspective, RPSs are higher than the risk-neutral perception (Fig. 9). Risk-averse organizations are overly cautious given that twenty-five risks are in the priority focus zone with six sustainability risks (grid pattern) including R34, R14, R13, R16, R12 and R19, categorized as very high priority risks and the remaining nineteen (solid pattern) as high priority. Only one of the sustainability risks (wave pattern) fell into the low priority group. 


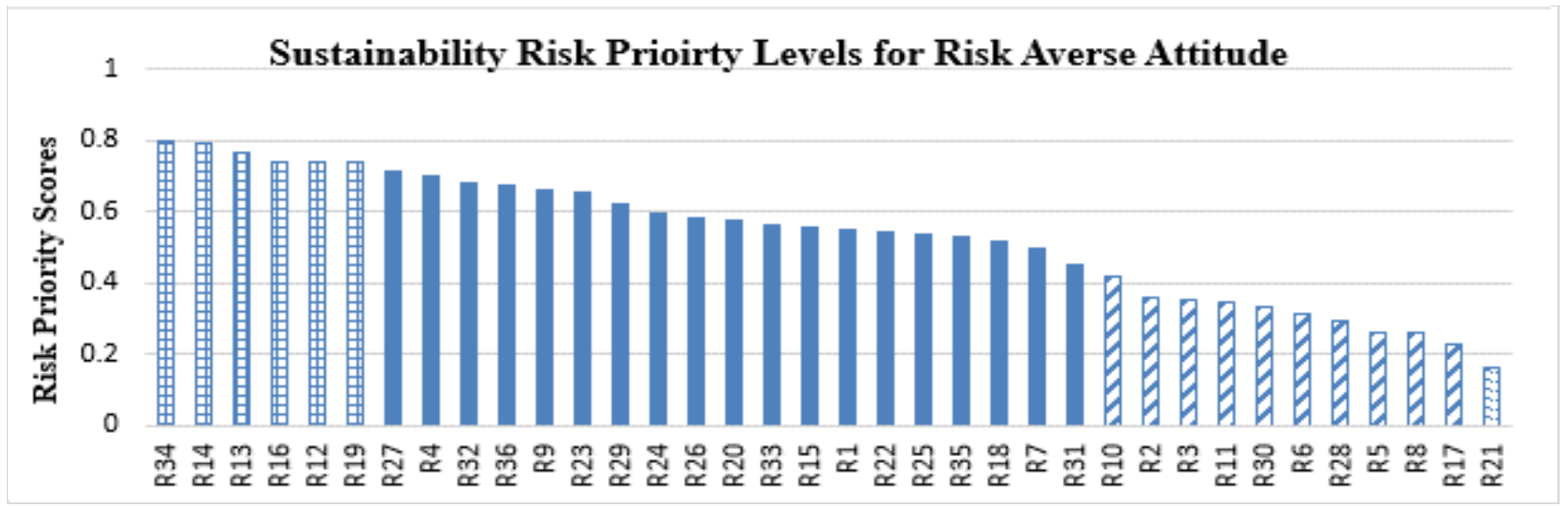

Fig. 10. Priority Order of Sustainability Risks for Risk-Averse Attitude

\subsection{Implications for Practitioners}

Sustainability is a well addressed topic in the FT literature but not so from a risk perspective. Hence, the question remains that what are the sustainability risks present in FT and how detrimental these risks could be to organizations. This study is the first to investigate and evaluate the magnitude and severity of sustainability risks in the context of FTSs. It provides a taxonomy and detailed understanding of sustainability risks to freight managers that can help them in appropriate decision making. The priority rankings of sustainability risks can be used by the freight companies with different risk preferences (risktaking, risk-neutral and risk-averse) in optimal allocation of mitigation resources to achieve sustainability goals. The research findings determine the critical aspects of FT that require improvement from the risk management perspective to facilitate the development of SFTSs

Research indicates that high social performance is necessary for the development of SFTSs as most of the high priority sustainability risks have a social dimension. Majority of the sustainability risks in FT including R34, which has the highest priority ranking arise due to behavioral and skill issues. Accordingly, instead of primarily focusing on economic aspects, freight companies need to pursue solutions for building moral and skill capital to surmount the sustainability risks present in FT. These solutions include hiring logistically competent employees, specialized training programs and incentives to improve driver skills, workshops to create awareness and willingness towards sustainability adoption, investment in sustainable technologies, 
building healthy working environment and following sustainability laws. Organizations need to develop freight collaborations so that fleet movements are sustainable through freight consolidation, back loading, full truck loads etc. For FT to be truly sustainable, organizations should not place cost-reductions atop as successful attainment of SFTSs can automatically lead to overall financial benefits. The research offers managerial insights considering different risk behaviors including an emphasis on improving social practices especially concerning behavioral and skill aspects to overcome the sustainability risks in FTSs.

\subsection{Sensitivity Analysis}

Sensitivity analysis is applied to investigate the sensitivity of the risk model output based on minor changes in inputs (which in this case are the belief degrees associated with linguistic terms). In order to verify the consistency and inference reasoning of the methodology, the risk model must pursue the following axioms (Yang et al., 2009):

Axiom 1: A minor decrease in the model input, such as the belief degree of a linguistic variable associated with the lowest level criteria should certainly cause a decrease in the model output, i.e., risk priority levels. Axiom 2: A minor increase in the model input, such as belief degree of a linguistic variable associated with the lowest level criteria should certainly cause an increase in the model output, i.e., risk priority levels. Axiom 3: If the belief degrees associated with the most preferred evaluation term for the lowest level criterion are reduced by $x$ and $y$, such that $1>x>y$ and simultaneously the belief degrees associated with the least preferred evaluation term for the lowest level criterion are increased by $\mathrm{x}$ and $\mathrm{y}$, then the utility value calculated for the model's output, i.e., $U_{x}$ and $U_{y}$, respectively, are in the order $U_{y}>U_{x}$.

To conduct the analysis, for each sustainability risk, the belief degree assigned to the most preferred evaluation term is reduced by $\mathrm{x}$ while simultaneously the belief degree assigned to the least preferred evaluation term is increased by $\mathrm{x}$ in the judgment of Expert 1, and, accordingly, RPSs are computed. It is worth noting that when reducing the belief degree, $\alpha_{\mathrm{n}}$, of the most preferred evaluation term for a risk by $\mathrm{x}$, if $x>\alpha_{n}$, the outstanding belief degree is reduced from the next evaluation term until $x$ is consumed (John et al., 2014). The RPSs obtained by reducing the belief degrees by $10 \%, 20 \%, 30 \%$ and $40 \%$, are presented 
in Table IX and the sensitivity of results is graphically depicted in Fig. 11. It should be noted that the results are in agreement with Axioms 1, 2 and 3.

Table IX: Risk Priority Scores Obtained by Reducing the Belief Degrees by 10\%, 20\%, 30\% and 40\%

\begin{tabular}{|c|c|c|c|c|c|c|}
\hline Risk Categories & Sustainability Risks & RPSs & $10 \%$ & $20 \%$ & $30 \%$ & $40 \%$ \\
\hline \multirow{4}{*}{ Fleet Management Risk } & $\mathrm{R} 1$ & 0.4201 & 0.3953 & 0.3778 & 0.3606 & 0.3429 \\
\hline & $\mathrm{R} 2$ & 0.2663 & 0.2481 & 0.2298 & 0.2195 & 0.2102 \\
\hline & R3 & 0.2609 & 0.2426 & 0.2258 & 0.2165 & 0.2071 \\
\hline & $\mathrm{R} 4$ & 0.5762 & 0.5513 & 0.5267 & 0.5028 & 0.4847 \\
\hline \multirow{4}{*}{ Financial Risks } & R5 & 0.1876 & 0.1780 & 0.1683 & 0.1599 & 0.1599 \\
\hline & R6 & 0.224 & 0.2065 & 0.1891 & 0.1762 & 0.1664 \\
\hline & R7 & 0.375 & 0.3506 & 0.3310 & 0.3134 & 0.2956 \\
\hline & R8 & 0.1871 & 0.1697 & 0.1561 & 0.1461 & 0.1361 \\
\hline \multirow{3}{*}{ Informational Risks } & R9 & 0.5446 & 0.5184 & 0.4926 & 0.4728 & 0.4543 \\
\hline & R10 & 0.3193 & 0.3012 & 0.2879 & 0.2796 & 0.2711 \\
\hline & R11 & 0.2575 & 0.2320 & 0.2073 & 0.1874 & 0.1699 \\
\hline \multirow{8}{*}{$\begin{array}{c}\text { Ecological \& Social } \\
\text { Risks }\end{array}$} & R12 & 0.6165 & 0.5911 & 0.5680 & 0.5499 & 0.5316 \\
\hline & R13 & 0.6633 & 0.6455 & 0.6280 & 0.6107 & 0.5935 \\
\hline & R14 & 0.6844 & 0.6668 & 0.6495 & 0.6325 & 0.6158 \\
\hline & R15 & 0.4454 & 0.4293 & 0.4219 & 0.4152 & 0.4084 \\
\hline & R16 & 0.6175 & 0.5920 & 0.5709 & 0.5529 & 0.5346 \\
\hline & R17 & 0.1616 & 0.1517 & 0.1417 & 0.1317 & 0.1283 \\
\hline & R18 & 0.3956 & 0.3729 & 0.3560 & 0.3395 & 0.3235 \\
\hline & R19 & 0.6114 & 0.5871 & 0.5675 & 0.5493 & 0.5310 \\
\hline \multirow{4}{*}{ Market Risk } & R20 & 0.4494 & 0.4259 & 0.4081 & 0.3905 & 0.3732 \\
\hline & R21 & 0.1189 & 0.1088 & 0.0987 & 0.0887 & 0.0874 \\
\hline & R22 & 0.4169 & 0.3919 & 0.3686 & 0.3513 & 0.3336 \\
\hline & R23 & 0.5251 & 0.5003 & 0.4794 & 0.4612 & 0.4432 \\
\hline \multirow{8}{*}{ Operational Risks } & R24 & 0.4663 & 0.4385 & 0.4136 & 0.3909 & 0.3738 \\
\hline & R25 & 0.4239 & 0.3993 & 0.3762 & 0.3592 & 0.3427 \\
\hline & R26 & 0.4538 & 0.4290 & 0.4056 & 0.3887 & 0.3715 \\
\hline & R27 & 0.5863 & 0.5553 & 0.5313 & 0.5065 & 0.4862 \\
\hline & R28 & 0.2167 & 0.1915 & 0.1682 & 0.1507 & 0.1336 \\
\hline & R29 & 0.4958 & 0.4712 & 0.4505 & 0.4325 & 0.4146 \\
\hline & R30 & 0.2403 & 0.2196 & 0.2019 & 0.1844 & 0.1733 \\
\hline & R31 & 0.3426 & 0.3248 & 0.3119 & 0.3040 & 0.2960 \\
\hline \multirow{5}{*}{$\begin{array}{c}\text { Organizational \& } \\
\text { Governmental Risks }\end{array}$} & R32 & 0.5598 & 0.5338 & 0.5090 & 0.4903 & 0.4716 \\
\hline & R33 & 0.4437 & 0.4277 & 0.4112 & 0.4010 & 0.3941 \\
\hline & R34 & 0.6896 & 0.6644 & 0.6403 & 0.6231 & 0.6056 \\
\hline & R35 & 0.4037 & 0.3788 & 0.3569 & 0.3356 & 0.3178 \\
\hline & R36 & 0.5438 & 0.5191 & 0.4974 & 0.4793 & 0.4612 \\
\hline
\end{tabular}




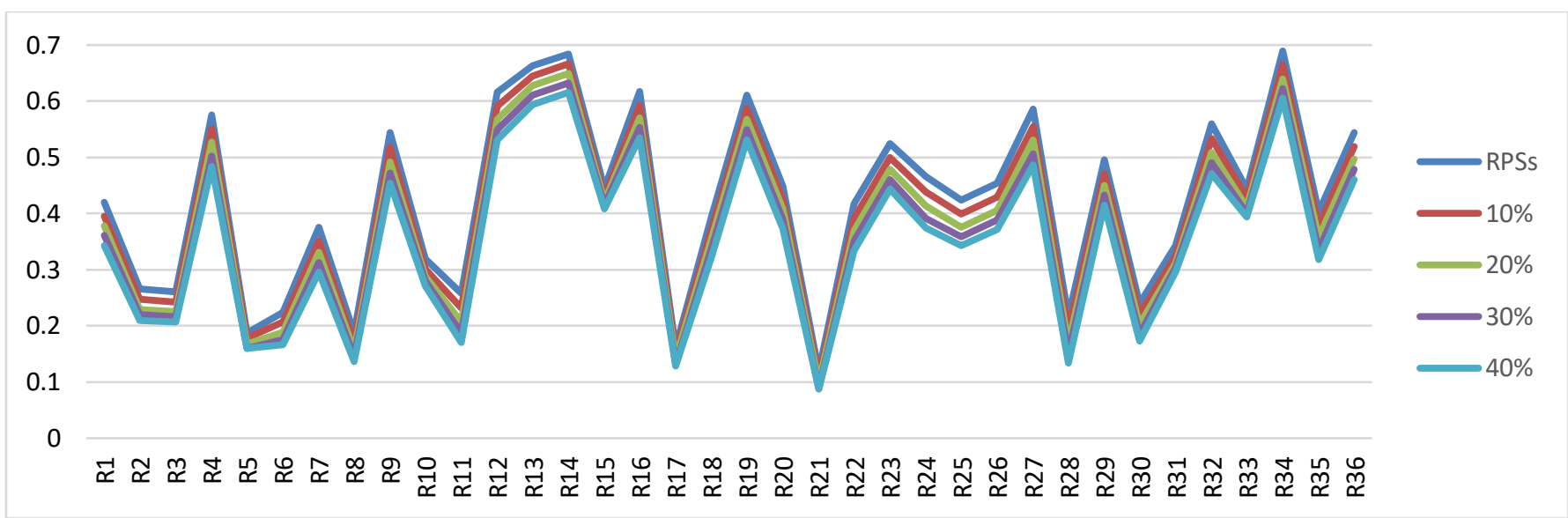

Fig.11: Sensitivity of RPSs to Variation in Input

Fig. 11 illustrates that the maximum variations occur in the RPS of R25 followed by R13. It suggests that these sustainability risks are most sensitive to Expert 1's opinion and hence are comparatively more significant to the corresponding organization. Only slight changes can be observed in the output, which reflect model reliability and show that significant changes in the ranking may occur only if all DMs are in agreement. Furthermore, the validation of axioms establishes that the risk model is robust and its inferences are rational (Yang et al., 2009).

\section{CONCLUSIONS}

Developing SFTSs is extremely complex and challenging due to the inherent sustainability risks. It is necessary to quantify and evaluate sustainability risks to facilitate the successful implementation of sustainability in FTSs. In line with this, this research seeks to evaluate the magnitude and severity of the consequences of sustainability risks associated with FT. Furthermore, sustainability risks are investigated for three ubiquitous scenarios namely risk-averse, risk-neutral and risk-taking to provide insights for organizations with different risk preferences. The results apprise the managers about the high priority sustainability risks inherent in FTSs and provide implications to pro-actively mitigate and control such risks. This study contribute to an emerging topic of sustainability risks where majority of the literature is either case-study based or conceptual and successfully addresses the research gaps acknowledged in some of the recent review papers (Fahimnia et al., 2015; Brandenburg \& Rebs, 2015; Aven, 2016; Jaehn, 2016; 
Reefke \& Sundaram, 2017). To the best of our knowledge, our research s first of its kind to quantify and model sustainability risk in the context of FTs.

A risk management maturity model that facilitates the management of sustainability risks by enabling visibility, predictability and treatment in SFTSs is proposed. In line with the maturity model, a total of thirty-six sustainability risks present in FTSs are identified and classified under seven groups. An integrated methodology, FERA (based on the FST and ERA) is innovatively employed with EUT to quantitatively model the identified sustainability risks. This approach has the capability to better capture the uncertainties of freight operations and the subjectivity in expert opinions in a unified manner, while preserving the original characteristics of multiple attributes. One of the unique characteristics of this approach is that it obtains the risk priorities by aggregating the belief structures and developing consensus among all DMs using the D-S theory rather than taking the average scores. In case of all three risk preferences, lack of awareness and logistics skills is found to be the highest priority sustainability risk and hence, there is an imminent need to emphasize on building professional capabilities in the freight sector. The results signify that most of the high severity risks have a social component and can be curbed if organizations focus on improving moral and skill aspects in employees. The evaluation of different risk perspectives shows that the risk-taking organizations are quite casual in their approach towards risks as only eight risks fall into the high priority category compared to sixteen in case of risk-neutral behavior. On the other hand, risk-averse organizations are found to be over-cautious as twenty five sustainability risks are in the priority focus zone with six risks categorized as very high priority and the remaining nineteen as high priority. A sensitivity analysis confirms the stability of the proposed risk-model and the derived inferences.

The analytical results obtained in this study with the freight transportation context are consistent with prior studies in other domains. For example, Lee and Klassin (2008); Distelhorst, Hainmueller and Locke (2016) and Lee and Tang (2017) showed that skilled workforces and training programs are necessary to foster social and environmental capabilities in supply chains. The developed model is extremely flexible and can 
be used to transparently and comprehensively assess risks in complex scenarios considering different risk behaviors. The criteria selected can be adapted and their importance can vary according to the managerial preferences. The model functions based on the inputs of decision makers and hence can take into account the organizational context and goals to provide customized results.

The research adds value to the knowledge pool of sustainable freight transportation and provides a foundation framework to extend the work in the very promising area of sustainability risk management. It provides significant managerial insights about surmounting the sustainability risks. It is significant in the current scenario as it can contribute in improving the performance of sustainable systems, which is the key requirement in many sectors. In future research, measures to control and mitigate sustainability risks in FTSs may be identified and investigated.

\section{Acknowledgement}

Authors would like to acknowledge the funding support received through UK- India Education Research Initiative (UKIERI) and University Grant Commission (UGC) for project Ref No: UGC-UKIERI 2016-17067, titled "Advanced Analytics for Green and Resilient Supply Chain Decision Making".

\section{APPENDIX}

Table A1: Explanation of Sustainability Risks Present in FTSs

\begin{tabular}{|c|l|}
\hline Sustainability Risks & \multicolumn{1}{|c|}{ Description } \\
\hline I) Fleet Management (FM) Risks \\
\hline Vehicle Utilization Risk (R1) & $\begin{array}{l}\text { Risk pertaining to the poor load factor running of transportation vehicles, which can be due to } \\
\text { capacity mismanagement or inefficient planning and leads to wastage of resources (manpower, } \\
\text { fuel, money etc.) and unnecessary emissions. }\end{array}$ \\
\hline $\begin{array}{c}\text { Insufficient Vehicle Range } \\
\text { (R2) }\end{array}$ & $\begin{array}{l}\text { In case of single vehicle configuration or if the desired configuration is unavailable, goods are } \\
\text { forcefully transported in the vehicle at hand irrespective of order size, volume and type of } \\
\text { commodity which can result in product damage, inefficient vehicle utilization etc. }\end{array}$ \\
\hline Fleet Capacity Risk (R3) & $\begin{array}{l}\text { Insufficient fleet capacity increases chances of disruptions and delays in freight operations thereby } \\
\text { can adversely affect the performance of sustainable transportation and customer satisfaction. }\end{array}$ \\
\hline Empty Running Risk (R4) & $\begin{array}{l}\text { Empty running of transportation vehicles between delivery and pickup points, during back haulage } \\
\text { etc. can negatively impacts the overall vehicle utilization and fuel efficiency. }\end{array}$ \\
\hline II) & Financial (FI) Risks \\
\hline Capital Sourcing Risks (R5) & $\begin{array}{l}\text { Uncertainty about the availability of huge initial capitals or funding sources required for } \\
\text { establishing sustainability in freight transportation operations. }\end{array}$ \\
\hline
\end{tabular}




\begin{tabular}{|c|c|}
\hline Financial Breakdown (R6) & $\begin{array}{l}\text { Risk of huge economic losses due to poor financial plans or investment failures or unsuccessful } \\
\text { business ventures that in turn will hamper the freight transportation functioning. }\end{array}$ \\
\hline Fuel Price Volatility (R7) & $\begin{array}{l}\text { Unpredictable rise in the fuel prices affects the transportation costs and disrupts the financial budget } \\
\text { of freight operations. }\end{array}$ \\
\hline Macro Risk (R8) & $\begin{array}{l}\text { Risk associated with the macroeconomic or political factors such as exchange rate, changing } \\
\text { monetary policies, interest rate, tax evasion etc }\end{array}$ \\
\hline \multicolumn{2}{|c|}{ Informational (IN) Risks } \\
\hline \begin{tabular}{|c|} 
Outbound \& Inbound \\
Logistics Disintegration (R9)
\end{tabular} & $\begin{array}{l}\text { Lack of coordination and information sharing between inbound and outbound logistics can result } \\
\text { in increased empty running, back haulage and creates need for unnecessary extra trips. }\end{array}$ \\
\hline ICT inadequacy Risk (R10) & $\begin{array}{l}\text { Ineffective and technologically outdated information system leads to serious problems such as } \\
\text { unavailability of real time data about traffic congestions and weather conditions, lack of GPS } \\
\text { routing, inability to track and trace vehicles thereby, highly enhances the chances of transportation } \\
\text { disruptions. }\end{array}$ \\
\hline $\begin{array}{l}\text { Information Dissemination } \\
\text { Risk (R11) }\end{array}$ & $\begin{array}{l}\text { Distortion and asymmetry in information flow increases the invisibility and uncertainty in } \\
\text { transportation operations affecting the integration across the logistic triad that can lead to demand } \\
\text { amplification and interruption of sustainable freight practices. }\end{array}$ \\
\hline \multicolumn{2}{|c|}{ Ecological \& Social (E\&S) Risks } \\
\hline Global Warming risk (R12) & $\begin{array}{l}\text { Extensively increasing greenhouse gas emissions from freight transportation are largely } \\
\text { contributing to the risk of global warming and severe climatic changes. }\end{array}$ \\
\hline $\begin{array}{l}\text { Unpredictable Traffic } \\
\text { Congestions (R13) }\end{array}$ & $\begin{array}{l}\text { Erratic road congestions results in increased delay, poor fuel efficiency, extra miles due to route } \\
\text { conversion and stress on drivers, which impacts the sustainable performance of freight } \\
\text { transportation. }\end{array}$ \\
\hline $\begin{array}{l}\text { Escalating Rate of Pollution } \\
\qquad(\mathrm{R} 14)\end{array}$ & $\begin{array}{l}\text { Ever-growing freight transportation is further enhancing the pace of air, water, land and noise } \\
\text { pollution especially in urban areas due to which livability conditions are deteriorating very fast } \\
\text { raising a very dangerous threat to the human health and ecology. }\end{array}$ \\
\hline $\begin{array}{l}\text { Visual Intrusion \& Habitat } \\
\text { Fragmentation (R15) }\end{array}$ & $\begin{array}{l}\text { Increase in freight transportation is creating the requirement for additional transport infrastructure } \\
\text { that can lead to the exploitation of land, destruction of habitat and species and can also cause } \\
\text { interference with the vision of people. }\end{array}$ \\
\hline Safety \& Health Risk (R16) & $\begin{array}{l}\text { Risk of monetary as well as human life losses associated with the accidents of freight transportation } \\
\text { vehicles and risk concerning the impacts of anthropogenic emissions and other freight activities on } \\
\text { human health. }\end{array}$ \\
\hline Weather Disruptions (R17) & $\begin{array}{l}\text { Chances of disruptions in transportation operations due to sudden climatic changes or due to } \\
\text { extreme weather conditions. }\end{array}$ \\
\hline Workforce Exploitation (R18) & $\begin{array}{l}\text { Prevalence of an unhealthy working environment that involves pressurizing employees to work } \\
\text { extra time, payment of unfair wages, discrimination etc. and violates the rights of drivers and } \\
\text { workers }\end{array}$ \\
\hline Corruption (R19) & $\begin{array}{l}\text { Acceptance of money or other incentives by an employee in exchange for allowing illegal } \\
\text { business practices. }\end{array}$ \\
\hline Market (MR) I & Risk \\
\hline Demand Volatility (R20) & $\begin{array}{l}\text { Sudden increase in the demand of product requires shipping of unplanned extra volume that can } \\
\text { lead to additional trips and add to emissions and transportation cost. }\end{array}$ \\
\hline Green Image Risk (R21) & $\begin{array}{l}\text { Risk of tarnished green reputation in the market in case of getting unsustainable operational } \\
\text { practices exposed or due to the failure in adopting sustainable practices. }\end{array}$ \\
\hline $\begin{array}{l}\text { Geographical Demand } \\
\text { Imbalance (R22) }\end{array}$ & $\begin{array}{l}\text { Uneven distribution of demand across various regions impedes the consolidation of goods and } \\
\text { creates the need for more trips in different geographic directions that can result in ineffective } \\
\text { vehicle utilization, unnecessary emissions etc. }\end{array}$ \\
\hline Market Dynamics (R23) & $\begin{array}{l}\text { Risk arising as a result of uncertainty in market about the willingness to pay extra for sustainably } \\
\text { transported goods and due to huge market competition. }\end{array}$ \\
\hline Operational & P) Risks \\
\hline Delay Risk(R24) & $\begin{array}{l}\text { Risk pertaining to the negative impacts of transportation delays such as missing of allocated load, } \\
\text { disruption of next delivery schedule, originating need for extra trips etc. on the sustainability of } \\
\text { freight transfer systems. }\end{array}$ \\
\hline $\begin{array}{c}\text { Vehicle Routing \& Scheduling } \\
\text { Risk (R25) }\end{array}$ & $\begin{array}{l}\text { Inefficient route planning and scheduling of vehicles can result in empty running and increased } \\
\text { travel distance that will have a negative environment and economic impact simultaneously. }\end{array}$ \\
\hline Material Handling Risk (R26) & $\begin{array}{l}\text { Chances of product damage during transshipment or loading and unloading resulting in monetary } \\
\text { losses and wastage of resources involved. }\end{array}$ \\
\hline
\end{tabular}




\begin{tabular}{|c|c|}
\hline Driver Associated Risk (R27) & $\begin{array}{l}\text { Poor driver proficiency and skills can adversely impact the idling of vehicle, acceleration profile } \\
\text { and vehicle speed, which in turn directly affects the fuel efficiency, transit times and transportation } \\
\text { cost. }\end{array}$ \\
\hline Reverse Logistics Risks (R28) & $\begin{array}{l}\text { Uncertainty associated with the time and amount of returns and lack of integration between forward } \\
\text { and reverse logistics can hamper the sustainable functioning of transportation systems. }\end{array}$ \\
\hline Non-Standard Orders (R29) & $\begin{array}{l}\text { Transportation of highly customized orders negatively impacts the vehicle utilization capability } \\
\text { and causes wastage of fuel and unnecessary emissions. }\end{array}$ \\
\hline $\begin{array}{l}\text { Product Design \& Packaging } \\
\text { Inefficacy(R30) }\end{array}$ & $\begin{array}{l}\text { Insensitive design and packaging of products towards logistic requirements increase the prospects } \\
\text { of poor load factor, product damage, fuel wastage and unnecessary emissions. }\end{array}$ \\
\hline $\begin{array}{l}\text { Delivery Restrictions } \\
\text { Associated Risk (R31) }\end{array}$ & $\begin{array}{l}\text { Delivery restrictions can be counterproductive and can sometimes result in increased transportation } \\
\text { cost, extra trips and intensified emissions as they forces the transportation of same amount of } \\
\text { products in a tighter time window. }\end{array}$ \\
\hline Organizational & 1 \& Governmental (O\&G) Risks \\
\hline $\begin{array}{c}\text { Infrastructure \& } \\
\text { Technological } \\
\text { Bottleneck(R32) }\end{array}$ & $\begin{array}{l}\text { Lack of proper infrastructure and technological innovations will make the establishment of green } \\
\text { transportation systems impossible and use of technologically outdated old vehicles further } \\
\text { complicates the sustainability adoption. }\end{array}$ \\
\hline $\begin{array}{l}\text { Lack of Management } \\
\text { Commitment and Strategic } \\
\text { Competence (R33) }\end{array}$ & $\begin{array}{l}\text { Risk concerning lack of managerial vision for implementing sustainability in transportation system } \\
\text { and inability to integrate sustainable goals into the overall strategic goals of the organization. }\end{array}$ \\
\hline $\begin{array}{l}\text { Lack of Awareness \& } \\
\text { Logistics Skill (R34) }\end{array}$ & $\begin{array}{l}\text { Many industries are not aware about the benefits of adopting sustainable practices and have } \\
\text { shortage of employees having proficient understanding of logistics operations that complicates the } \\
\text { incorporation of sustainable practices in freight transportation system. }\end{array}$ \\
\hline $\begin{array}{l}\text { Unaligned goals of carrier and } \\
\text { shipper (R35) }\end{array}$ & $\begin{array}{l}\text { Possibility of disagreement between the shipper and carrier due to contradictory views about } \\
\text { incorporation of green practices in freight transportation. }\end{array}$ \\
\hline $\begin{array}{l}\text { Sustainable Regulation } \\
\text { Compliance Risk (R36) }\end{array}$ & $\begin{array}{l}\text { Risk of legal actions and government imposed penalties in case of non-compliance with sustainable } \\
\text { laws and regulations. }\end{array}$ \\
\hline
\end{tabular}

Table A2: Risk Priority Level in the form of (TFN) $)_{\mathrm{PI}} \&$ Normalized Intersection Results of Risk Issues

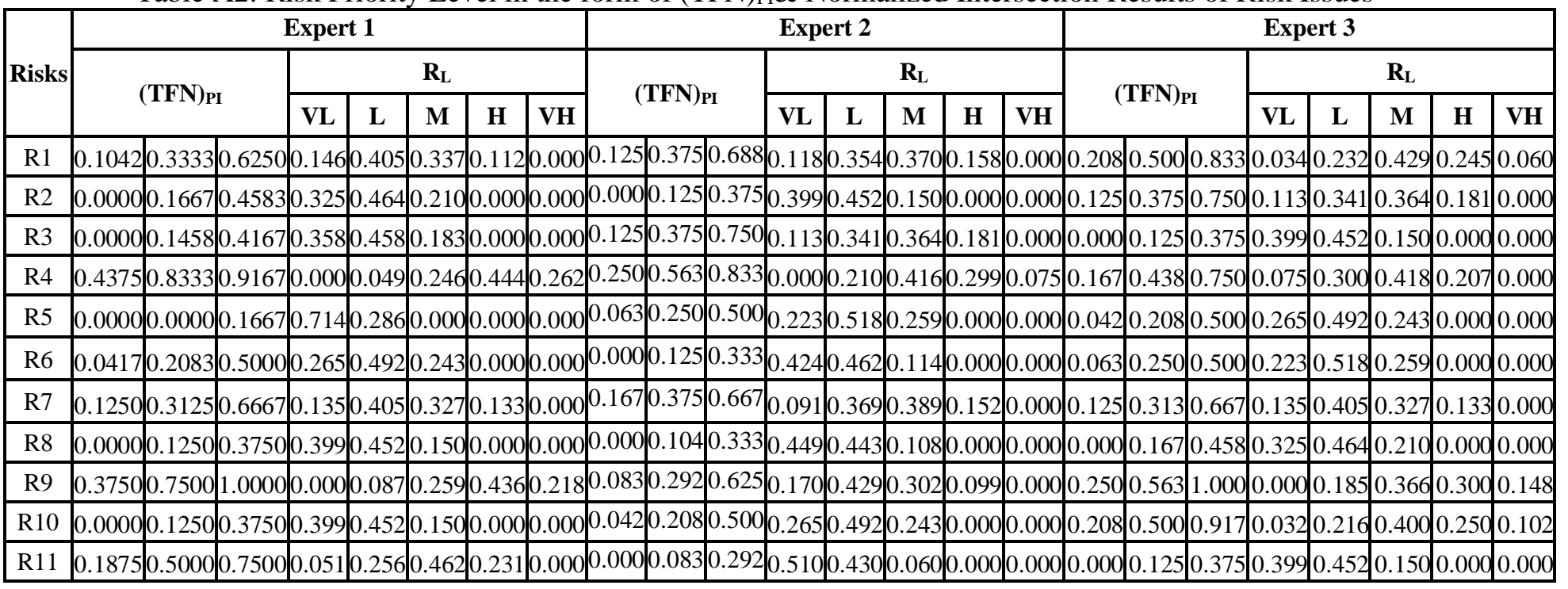




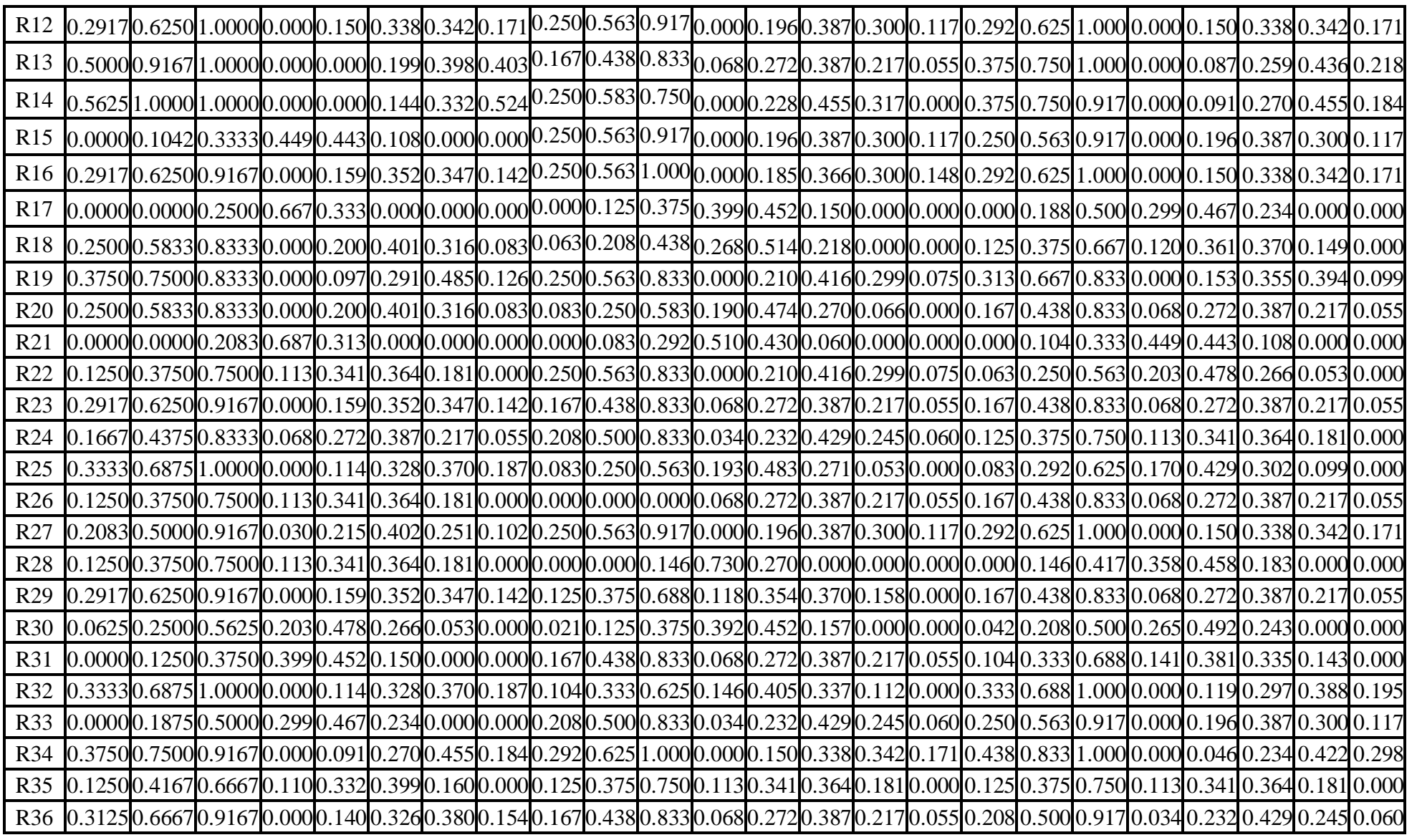

\section{REFERENCES}

Anand, A., Khan, R. A., \& Wani, M. F. (2016). Development of a sustainability risk assessment index of a mechanical system at conceptual design stage. Journal of cleaner production, 139, 258-66.

Anderson, D. R., \& Anderson, K. E. (2009). Sustainability risk management. Risk Management and Insurance Review, 12 (1), 25.

Aven, T. (2016). Risk assessment and risk management: Review of recent advances on their foundation. European Journal of Operational Research, 253(1), 1-13.

Aven, T. (2018). An Emerging New Risk Analysis Science: Foundations and Implications. Risk Analysis, 38 (5), 876-888.

Aven, T., Renn, O., \& Rosa, E. (2011). The ontological status of the concept of risk. Safety Science, 49, 1074-1091.

Aven, T, \& Renn, O. (2009). On risk defined as an event where the outcome is uncertain. Journal of Risk, 12, 1-11.

Avendus. (2016). Logistics-Tech, Available at: https://www.avendus.com/crypted_pdf_path/img_5b0c132287b340.82647301_logistics-tech-re-architecting-thenervous-system-of-the-economy.pdf; Accessed 15.04.2019.

Bai, C., Fahimnia, B., \& Sarkis J. (2017). Sustainable transport fleet appraisal using a hybrid multi-objective decision making approach. Annals of Operations Research, 250 (2), 309-340.

Brandenburg, M., \& Rebs, T. (2015). Sustainable supply chain management: a modeling perspective. Annals of Operations Research, 229, 213-252. 
Busse, C., Kach, A. P., \& Bode, C. (2016). Sustainability and the false sense of legitimacy: how institutional distance augments risk in global supply chains. Journal of Business Logistics 37(4), 312-28.

Busse, .C, Schleper, M. C., Weilenmann, J., \& Wagner, S. M. (2017). Extending the supply chain visibility boundary: utilizing stakeholders for identifying supply chain sustainability risks. International Journal of Physical Distribution \& Logistics Management, 47(1), 18-40.

Busse, C., Schleper, M. C., Weilenmann, J., \& Wagner, S. M. (2018). Extending the supply chain visibility boundary: Utilizing stakeholders for identifying supply chain sustainability risks. International Journal of Physical Distribution \& Logistics Management, 47 (1), 18-40.

Carter, C. R., \& Rogers, D. S. (2008). A framework of sustainable supply chain management: moving toward new theory. International Journal of Physical Distribution \& Logistics Management, 38 (5), 360-387.

Cavinto, J. L. (2004). Supply chain logistics risks-From the back room to the board room. International Journal of Physical Distribution \& Logistics Management, 34 (5), 383-387.

Chen, Y., Shu, L., \& Burbey, T. J. (2014). An Integrated Risk Assessment Model of Township-Scaled Land Subsidence Based on an Evidential Reasoning Algorithm and Fuzzy Set Theory. Risk Analysis, 34(4), 656-69.

Cui, I., Dodson, J., \& Hal, P. V. (2015). Planning for Urban Freight Transport: An Overview. Transport Reviews, 35(5), 58359.

Demir, E., Huang, Y., Scholts, S., \& Woensel, T. V. (2015). A selected review on the negative externalities of the freight transportation: Modeling and pricing. Transportation Research Part E, 77, 95-114.

Distelhorst, G., Hainmueller, J., \& Locke, R. M. (2016). Does lean improve labor standards? Management and social performance in the Nike supply chain. Management Science, 63(3), 707-28.

Dubey, R., \& Gunasekaran, A. (2015). The role of truck driver on sustainable transportation and logistics. Industrial and Commercial Training, 47 (3), 127 - 134.

ERTRAC Research and Innovation Roadmaps. (2011). Sustainable Freight System for Europe Green, Safe and Efficient Corridors. Available at:

http://www.ertrac.org/uploads/documents_publications/Roadmap/Sustainable\%20Freight\%20System\%20for\%20Eu rope $\% 20 \% 20 \mathrm{Green}, \% 20 \mathrm{Safe} \% 20$ and\%20Efficient\%20Corridors.pdf; Accessed 12.04.2019.

Fahimnia, B., Tang, C., Davarzani, H., \& Sarkis J. (2015). Quantitative models for managing supply chain risks: A review. European Journal of Operational Research, 247, 1-15.

Gan, L. (2003). Globalization of the automobile industry in China: dynamics and barriers in greening of the road transportation. Energy Policy, 31, 537-551.

Giannakis. M, \& Papadopoulos, T. (2016). Supply chain sustainability: A risk management approach. International Journal of Production Economics, 171 (4), 455-470.

Goldman, T., \& Gorham, R. (2006). Sustainable urban transport: Four innovative directions. Technology in Society, 28, 261273.

Govindan, K., \& Chaudhuri, A. (2016). Interrelationships of risks faced by third party logistics service providers: A DEMATEL based approach. Transportation Research Part E, 90, 177-195.

Harclerode, M. A., Macbeth, T. W., Miller, M. E., Gurr, C. J., \& Myers, T. S. (2016). Early decision framework for integrating sustainable risk management for complex remediation sites: drivers, barriers, and performance metrics. Journal of environmental management, 184, 57-66.

Heckmann, I., Comes, T., \& Nickel, S. (2015). A Critical Review on Supply Chain Risk-Definition, Measure and Modeling. Omega, 52, 119-132.

Hofmann, H., Busse, C., Bode, C., \& Henke, M. (2014). Sustainability-related supply chain risks: Conceptualization and management. Business Strategy and the Environment. 23(3), 160-72.

Jaehn, A. (2016). Sustainable operations. European Journal of Operational Research,253 (2), 243-264.

John, A., Paraskevadakis, D., Bury, A., Yang, Z., Riahi, R., \& Wang, J. (2014). An integrated fuzzy risk assessment for seaport operations. Safety Sciences, 68, 180-194.

Kim, S., Wagner, S. M., \& Colicchia, C. (2019). The Impact of Supplier Sustainability Risk on Shareholder Value. Journal of Supply Chain Management, 55(1), 71-87.

Lee, S. Y., \& Klassen, R. D. (2008). Drivers and enablers that foster environmental management capabilities in small-and medium-sized suppliers in supply chains. Production and Operations management, 17 (6), 573-86.

Lee, H. L., \& Tang, C. S. (2017). Socially and environmentally responsible value chain innovations: New operations management research opportunities. Management Science, 64 (3), 983-96.

Lindholm, M. (2010). A sustainable perspective on urban freight transport: Factors affecting local authorities in the planning procedures. Procedia Social and Behavioral Sciences, 2, 6205-6216.

Liu, H., Liu, L., Bian, Q., Lin, Q., Dong, N., \& Xu, P. (2011). Failure Mode and Effects Analysis using Fuzzy Evidential Reasoning Approach and Grey Theory. Expert Systems with Application, 38, 4403-4415. 
Mangla, S. K., Kumar, P., \& Barua, M. K. (2015). Risk analysis in green supply chain using fuzzy AHP approach: A case study. Resource Conservation \& Recycling, 104, 375-390.

Marchet, G., Melacini, M., \& Perotti, S. (2014). Environmental sustainability in logistics and freight transportation: A literature review and research agenda. Journal of Manufacturing Technology and Management, 25 (6), 775-811.

NTDPC. India Transport Report-Moving India to 2032. 2014; Available at: http://planningcommission.nic.in/reports/genrep/NTDPC_Vol_01.pdf; Accessed 17.03.2019

Piecyk, M., \& Mckinnon, A. C. (2010). Forecasting the carbon footprint of road freight transport in 2020. International Journal of Production Economics, 128, 31-42.

Raghuram, G. (2016). An overview of the trucking sector in India: Significance and structure. Trucking Business Management: Cases and Concepts; McGraw Hill Education.

Ravi, V., \& Shankar, R. (2004). Analysis of Interactions among the Barriers of Reverse Logistics. Technological Forecasting \& Social Change, 72, 1011-1029.

Reefke, H., \& Sundaram, D. (2017). Key Themes and Research Opportunities in Sustainable Supply Chain Management Identification and Evaluation. Omega, 66 (Part B), 195-211.

Reinerth, D., Busse, C., \& Wagner, S. M. (2019). Using Country Sustainability Risk to Inform Sustainable Supply Chain Management: A Design Science Study. Journal of Business Logistics, 40 (3), 241-264.

Richardson, B. C. (2005). Sustainable transport: analysis frameworks. Journal of Transport Geography, 13, 29-39.

Rodrigues, V. S., Potter, A., \& Naim, M. (2010). The impact of logistics uncertainty on sustainable transport operations. International Journal of Physical Distribution \& Logistics Management, 40 (1/2): 61 - 83.

Schlegel, G. L., \& Trent, R. J. (2015). Supply Chain Risk Management: an Emerging Discipline. New York, CRC Press, Taylor \& Francis Group.

Schliwa, G., Armitage, R., Aziz, S., \& Evans, J. (2015). Sustainable city logistics-Making cargo cycles viable for urban freight transport. Research in Transportation Business \& Management, 15, 50-57.

Shafer, G. (1976). A Mathematical Theory of Evidence. Princeton University Press, New Jersey.

Shafiq, A., Johnson, P. F., Klassen, R. D., 7 Awaysheh, A. (2017). Exploring the implications of supply risk on sustainability performance. International Journal of Operations \& Production Management, 37(10), 1386-407.

Shankar, R., Choudhary, D., \& Jharkharia, S. (2018). An integrated risk assessment model: A case of sustainable freight transportation systems. Transportation Research Part D: Transport and Environment, 63, 62-676.

Song, W., Ming, X., \& Liu, H. C. (2017). Identifying critical risk factors of sustainable supply chain management: A rough strength-relation analysis method. Journal of Cleaner Production, 143, 100-15.

Srivastava, S. K. (2006). Logistics and supply chain practices in India. Vision: The Journal of Business Perspective,10 (3), 69-79.

Stackelberg, K.E. (2013). Decision analytic strategies for integrating ecosystem services and risk assessment. Integrated environmental assessment and management, 9(2), 260-8.

SteadieSeifi, M., Dellaert, N. P., Nuijten, W., Woensel, T. V., \& Raoufi, R. (2014). Multimodal freight transportation planning: A literature review. European Journal of Operational Research, 233, 1-15.

Stank, T. P., \& Goldsby, T. F. (2000). A Framework for Transportation Decision Making in an Integrated Supply Chain. Supply Chain Management: An International Journal, 5 (2), 71-77.

Su, X., Mahadevan, S., Xu, P., \& Deng, Y. (2015). Dependence assessment in human reliability analysis using evidence theory and AHP. Risk Analysis, 35(7), 1296-31

Torres-Ruiz, A., \& Ravindran, A. R. (2018). Multiple criteria framework for the sustainability risk assessment of a supplier portfolio. Journal of cleaner production, 172, 4478-93.

Valinejad, F., \& Rahmani, D. (2018). Sustainability risk management in the supply chain of telecommunication companies: A case study. Journal of cleaner production. 203, 53-67.

Velazquez, N. L., Munguia, N. E., Will, M., Zavala, A. G., Verdugo, S. P., Delakowitz, B., \& Giannetti, B. (2015). Sustainable transportation strategies for decoupling road vehicle transport and carbon dioxide emissions. Management of Environmental Quality: An International Journal, 26 (3), 373 - 388.

Von Neumann, J. R., \& Morgenstern, O. (1947). Theory of games and economic behavior. Princeton University Press.

Wang, Y., Yang, J., \& Xu, D. (2006). Environmental impact assessment using the evidential reasoning approach. European Journal of Operational Research, 174, 1885-1913.

Wang, Y., Rodrigues, V. S., \& Evans, L. (2015). The use of ICT in road freight transport for CO2 reduction - an exploratory study of UK's grocery retail industry. The International Journal of Logistics Management, 26 (1), 2 - 29.

WEO. (2015). India Energy Outlook. http://www.worldenergyoutlook.org/media/weowebsite/2015/IndiaEnergyOutlook_WEO2015.pdf/; Accessed 15.06.2017. 
Wu, B., Yan, X., Wang, Y., \& Soares, C. G. (2017). An Evidential Reasoning-Based CREAM to Human Reliability Analysis in Maritime Accident Process. Risk analysis, 37(10), 1936-57.

Weber, E. U., \& Milliman, R. (1997). Perceived risk attitudes: relating risk perception to risky choice. Management Science, $43,122-143$.

Wijethilake, C., \& Lama, T. (2019). Sustainability core values and sustainability risk management: Moderating effects of top management commitment and stakeholder pressure. Business Strategy and the Environment, 28(1), 143-54.

Yang, J. B. (2001). Rule and utility Based Evidential Reasoning Approach for Multi-Attribute Decision Analysis Under Uncertainties. European Journal of Operational Research, 131, 31-61.

Yang, Z., Wang, J., Bonsall, S., \& Fang, Q. (2009). Use of fuzzy evidential reasoning in maritime security assessment. Risk Analysis, 29 (1), 95-120.

Zadeh, L. A. (1965). Fuzzy Sets. Information and Control, 8, 338-353. 